\title{
LLC and CLLC Resonant Converters Based DC Transformers (DCXs): Characteristics, Issues, and Solutions
}

\author{
Yuqi WEI, Quanming LUO, and Homer Alan MANTOOTH
}

\begin{abstract}
Conventional line frequency transformers have the disadvantages of large volume and low efficiency. The medium or high frequency transformers based on power converters can achieve high power conversion with small footprint have drawn popularity in numerous industrial applications. Unregulated resonant converters, LLC and CLLC resonant converters, with fixed voltage conversion ratio operating at resonant frequency, which are also known as DC transformers (DCXs), are attractive owning to their high efficiency characteristic. Nevertheless, there are issues associated with DCXs in real applications. Regulation capability and automatic resonant frequency tracking capability are the two most important issues for DCXs. The main work of this paper is to characterize the resonant converters based DCXs, and overview the issues and solutions associated with DCXs. Guidelines can be provided for researchers and engineers when designing the resonant converters based DCXs.
\end{abstract}

Index Terms-DC transformer (DCX), regulation capability, resonant converter, resonant frequency tracking.

\section{INTRODUCTION}

$\mathrm{W}$ ITH the ever increasing concerns on energy crisis and environmental problems, there are great demands on renewable energy sources [1]-[3]. Fig. 1 shows the typical structure of a hybrid AC/DC microgrid [4], [5]. Conventionally, the $\mathrm{AC} / \mathrm{DC}$ unit is achieved by the conventional line frequency $\mathrm{AC} / \mathrm{AC}$ transformer and $\mathrm{AC} / \mathrm{DC}$ rectifier as shown in Fig. 2(a). In order to remove the large-footprint conventional line frequency transformer, the DC transformer (DCX) concept is introduced, where the AC/DC unit is achieved by an AC/DC rectifier unit and a DC/DC unit as shown in Fig. 2(b) [6]. The DC/DC unit can be implemented by a DC transformer. Among different DC/DC converter topologies, resonant converters, LLC and CLLC resonant converters, have drawn much atten-

Manuscript received January 10, 2021; revised March 12, 2021; accepted May 20, 2021. Date of publication December 30, 2021; date of current version December 24, 2021. (Corresponding Author: Yuqi Wei.)

Y. Wei and H. A. Mantooth are with the Department of Electrical Engineering University of Arkansas, Fayetteville, AR 72701 USA (e-mail: yuqiwei@uark.edu; mantooth@uark.edu).

Q. Luo is with the State Key Laboratory of Power Transmission Equipment and System Security and New Technology, School of Electrical Engineering, Chongqing University, China, and is with School of Electrical Engineering, Shaanxi University of Technology (e-mail: lqm394@126.com).

Digital Object Identifier 10.24295/CPSSTPEA.2021.00031

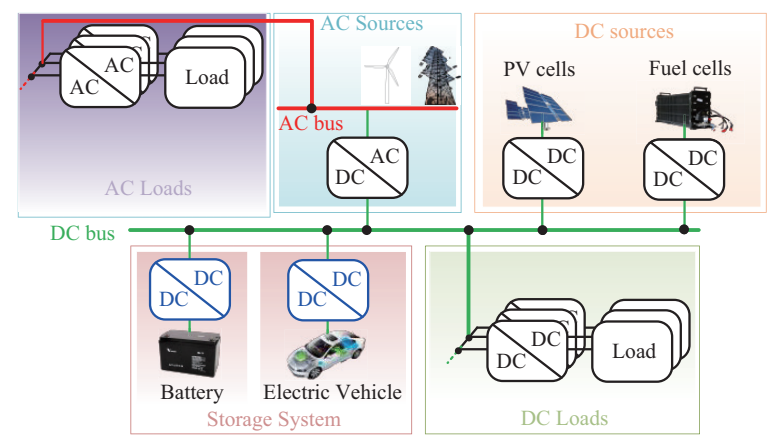

Fig. 1. Typical structure of the hybrid AC/DC microgrid.

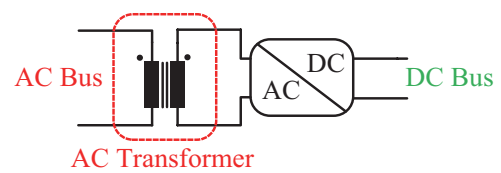

(a) Conventional AC transformer

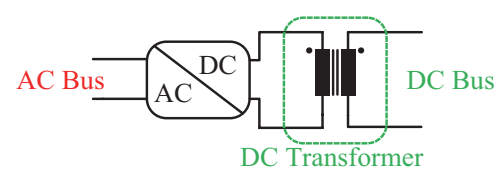

(b) DC transformer

Fig. 2. Implementation of the AC/DC unit in the hybrid AC/DC microgrid.

tion due to the following advantages [7]-[15]:

1) Soft switching operation capability from full-load to noload.

2) No filtering inductor is required on the secondary side.

3)When the resonant converter is operating at resonant frequency, the converter voltage gain is unity and independent of the load.

4) The resonant inductor and transformer can be easily integrated with one power transformer.

5) The resonant capacitor has the DC current blocking capability, which is favorable for isolation transformer.

6) Bi-directional operation capability. Both LLC and CLLC resonant converters have the bi-directional operation capability, which is favored in microgrid applications, where bi-directional power flow is required between the energy storage systems.

There are many different resonant converter topologies 
based on the primary inverter structure and secondary rectifier structure [16]. The general topology selection guideline can be summarized as follows:

1) For the primary inverter structure, the stacked structure can be used in high input voltage applications to reduce the voltage stress on the semiconductors; the full-bridge structure is favored in high power applications, while the half-bridge is favored in low power applications with reduced number of semiconductors.

2) For the secondary rectifier, the voltage doubler rectifier is preferred in high step-up applications; the full-bridge rectifier is favored in high output voltage applications; the center-tapped transformer rectifier structure is advantageous in low output voltage and high output current applications.

3) The synchronous rectification (SR) is adopted in both the high output current conditions and applications require bi-directional power flow.

In addition to the application of DCXs in power conversion from $\mathrm{AC}$ bus to $\mathrm{DC}$ bus in the hybrid $\mathrm{AC} / \mathrm{DC}$ microgrid, there are many other places that DCXs can be applied. The resonant converters based DCXs have been widely used in high voltage direct current (HVDC) systems [17], residential photovoltaic (PV) generation systems [18], and on-board battery chargers [19], and server power supplies [20].

In this article, comprehensive analysis on the DCXs has been made from different perspectives. To start with, the characterizations on the resonant converters based DCXs have been implemented from different perspectives to demonstrate the advantages of fixed switching frequency operation of DCXs. Then, the two major issues, output regulation capability and automatic resonant frequency tracking capability, of DCXs are analyzed and summarized. Overviews and comparisons on the existing solutions for these two major issues are made. The advantages and disadvantages of each solution are summarized to provide guidance for engineers when designing a resonant converter based DCX.

\section{Characterizations of Resonant Converters Based DC TRANSFORMER}

In this section, characterizations of resonant converters based DCXs are implemented to demonstrate their advantages and unique characteristics. Fig. 3(a) shows the overall structure of the resonant converter. The selection guidelines for different inverter and rectifier structures are discussed in Introduction. In this section, the analysis and characterizations are based on the half-bridge LLC (HBLLC) resonant converter as shown in Fig. 3(b). Please note the analysis results can also be applied for other LLC converters and CLLC converters.

\section{A. Unity Gain Characteristic for DCX}

According to the First Harmonic Approximation (FHA) analysis, the LLC resonant converter circuit model can be derived as shown in Fig. 4 [16]. $V_{\mathrm{ac}}$ and $V_{\mathrm{pl}}$ are the fundament harmonic of primary inverter output voltage and transformer

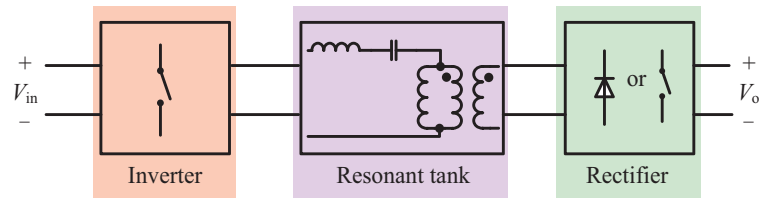

(a) Overall structure

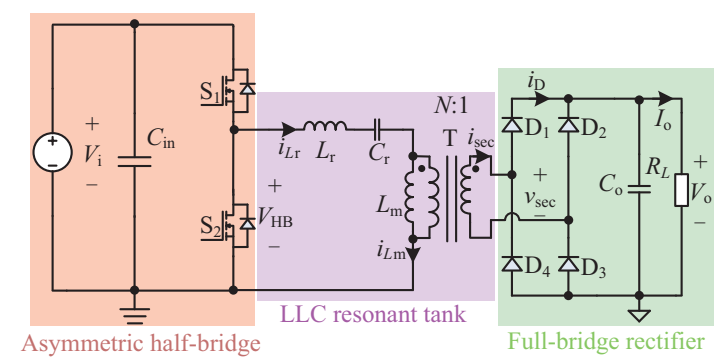

(b) Half-bridge LLC converter

Fig. 3. Overall system structure of the resonant converter.

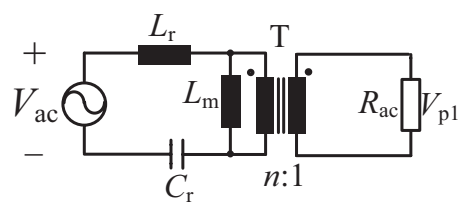

(a) LLC resonant converter

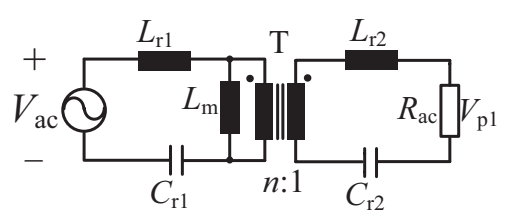

(b) CLLC resonant converter

Fig. 4. FHA circuit model for LLC and CLLC resonant converters.

secondary side voltage. $R_{\mathrm{ac}}$ is the equivalent $\mathrm{AC}$ resistance of the secondary rectifier network.

Based on the Fourier analysis and voltage divider law, the following expressions can be derived.

$$
\begin{gathered}
V_{\mathrm{pl}}(s)=V_{\mathrm{ac}} \frac{\frac{L_{\mathrm{m} S} R_{\mathrm{ac}}}{L_{\mathrm{m} S}+R_{\mathrm{ac}}}}{L_{\mathrm{r} S}+\frac{1}{C_{\mathrm{r} S}}+\frac{L_{\mathrm{m} S} R_{\mathrm{ac}}}{L_{\mathrm{m} S}+R_{\mathrm{ac}}}} \\
R_{\mathrm{ac}}=\frac{8 n^{2}}{\pi^{2}} R_{L}
\end{gathered}
$$

When the LLC resonant converter is operating at the resonant frequency, the term $\left(L_{\mathrm{r}} \mathrm{s}+1 / C_{\mathrm{r}} \mathrm{s}\right)$ in (1) equals 0 . Similarly, for the CLLC resonant converter in Fig. 4(b), there is no voltage drop on the primary side $L_{\mathrm{r} 1}, C_{\mathrm{r} 1}$ and secondary side $L_{\mathrm{r} 2}, C_{\mathrm{r}}$. Thus, the fundamental harmonic of primary side equals the fundamental harmonic of secondary side, which demonstrates the constant voltage gain characteristic of CLLC resonant converter.

Therefore, the voltage gain for the resonant converter based DCX is unity and it is independent of the load. Fig. 5(a) shows the voltage gain curves for LLC resonant converter when in- 


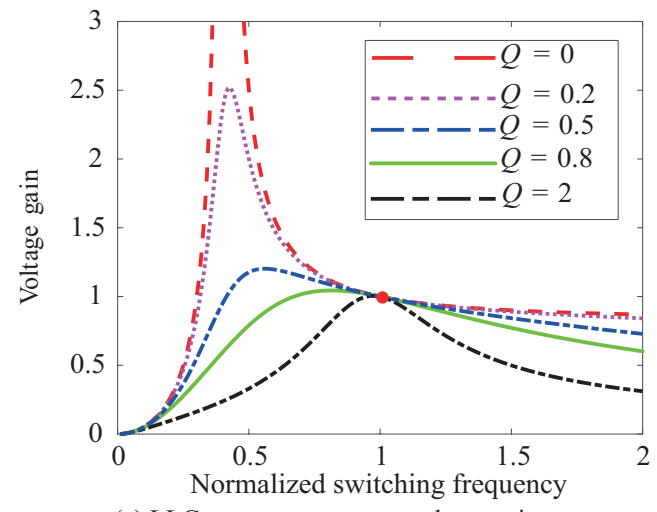

(a) LLC resonant converter voltage gain curve

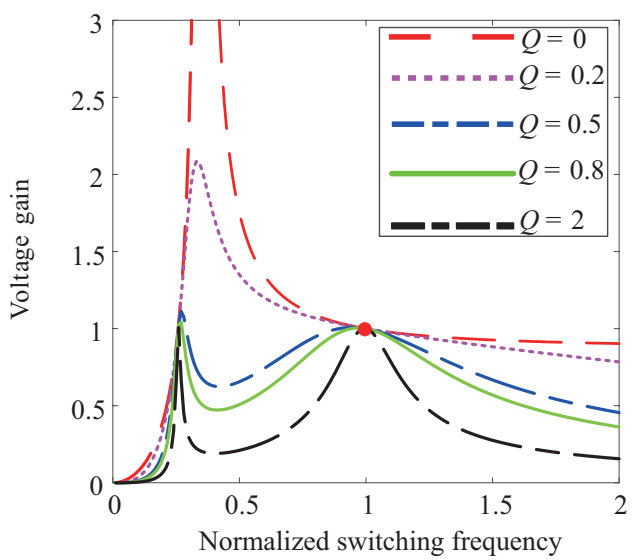

(b) CLLC resonant converter voltage gain curve

Fig. 5. Voltage gain curves under different load conditions for resonant converters.

ductor ratio $K$ equals 5 under different load conditions. Please note that the inductor ratio $K$ and quality factor $Q$ are defined as: $K=L_{\mathrm{m}} / L_{\mathrm{r}}, Q=\sqrt{L_{\mathrm{r}} / C_{\mathrm{r}}} / R_{\mathrm{ac}}$. Clearly, when operating at resonant frequency point, the resonant converter voltage gain is fixed and independent of load. Similarly, for CLLC resonant converter, as shown in Fig. 5(b), the converter voltage gain is unity and independent of the load at resonant frequency operation.

\section{B. Efficiency Comparison for Different Operation Regions}

For LLC/CLLC resonant converter, there are three different operation regions: below resonant frequency, above resonant frequency, and at resonant frequency. The following analysis and comparisons are made based on the half-bridge LLC converter with the following specific circuit parameters: $C_{\mathrm{r}}=66 \mathrm{nF}$, $L_{\mathrm{r}}=38 \mu \mathrm{H}, L_{\mathrm{m}}=200 \mu \mathrm{H}, n=5, V_{\mathrm{o}}=40 \mathrm{~V}, P_{\mathrm{o}}=1 \mathrm{~kW}$.

Fig. 6 shows the LLC resonant converter operating in different operation regions. In Fig. 6(a), the LLC converter is operating in below resonant frequency region, the circuit circulating energy is large and the corresponding conduction loss is large. In Fig. 6(b), the LLC resonant converter is operating in above resonant frequency region, although the circulating energy is reduced, the primary switch turn-off current and corresponding switching loss are increased. In addition, due to the continuous operation of the secondary rectifier, the zero-current turn-off

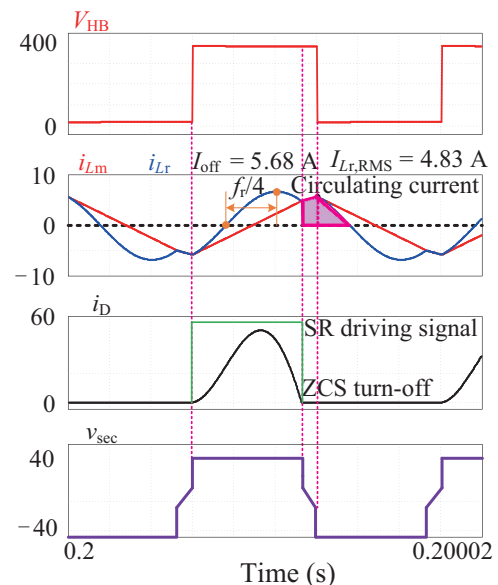

(a) Below resonant frequency operation

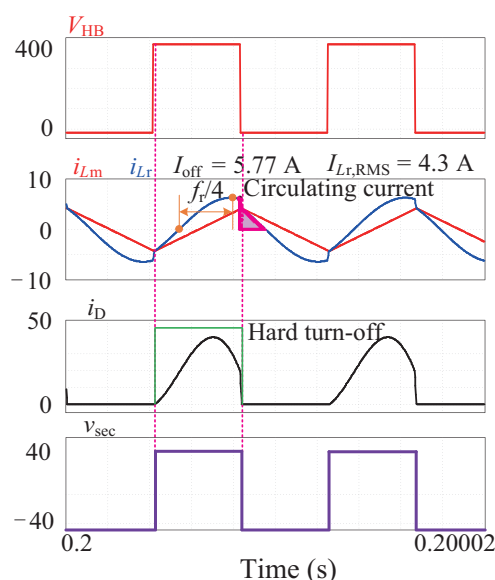

(b) Above resonant frequency operation

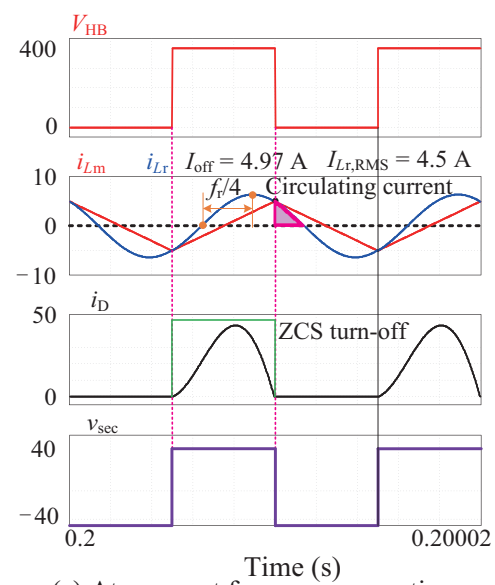

(c) At resonant frequency operation

Fig. 6. Simulation waveforms for LLC resonant converter under different operation regions.

for the secondary rectifier is lost in above resonant frequency operation region. The optimal operating point for LLC resonant converter is at resonant frequency operation point as shown in Fig. 6(c), where the circulating energy is minimized and the semiconductors switching losses are reduced simultaneously.

This optimal operating point for LLC resonant converter has been well validated in the literature [19]. 


\section{Synchronous Rectification for Different Operation Regions}

One of the advantages for DCXs is that the implementation of synchronous rectification (SR) is very simple, which can be regarded as the same as the primary switching driving signal with fixed switching frequency and duty cycle. However, for other operation regions, there are discrepancies between the SR driving signal and the primary switch driving signal as show in Fig. 6 [20]. Most of the SR driving strategies are based on the SR body diode conduction status, which require high bandwidth comparator and high speed digital controller. However, due to the reduced reliability of these complicated SR driving schemes, they are not preferred in high power applications, where the system reliability is of great importance. Therefore, the DCXs have been widely used in high power applications due to their high reliability operation characteristic, like medium voltage solid state transformer [23].

\section{Zero-Voltage Switching (ZVS) Analysis for Different Op- eration Regions}

Although the resonant converters can be designed to operate in inductive region during the whole operation range, the relationship between the ZVS operation for primary switch and the load condition is quite different for different operation regions. This phenomenon can be simply explained by using the FHA circuit model as shown in Fig. 4. When the converter is not operating at resonant frequency, the voltage across the magnetizing inductor is no longer clamped by the input voltage/output voltage since the voltage drop across the series connection of resonant inductor and resonant capacitor is not zero. While at resonant frequency point operation, there is no voltage drop on the series connection of resonant capacitor and resonant inductor. Moreover, the voltage drop is greatly affected by the load current (which will affect the primary resonant tank current) and impedance of resonant inductor and resonant capacitor or switching frequency. Therefore, the current during deadtime operation is greatly affected by the switching frequency and output power. Therefore, different deadtime is preferred to improve the converter performance.

To further demonstrate the relationship between the ZVS operation and converter operation regions, a specific half-bridge LLC resonant converter is investigated to check the minimum deadtime in different operating conditions. The converter specifications are summarized as follows: input voltage $V_{\mathrm{i}}$ : $160 \mathrm{~V}-240 \mathrm{~V}$; output voltage $V_{\mathrm{o}}: 25 \mathrm{~V}$; output power $P_{\mathrm{o}}: 12.5$ W-125 W; resonant capacitor $C_{\mathrm{r}}: 66 \mathrm{nF}$; resonant inductor $L_{\mathrm{r}}$ : $38 \mu \mathrm{H}$; magnetizing inductor $L_{\mathrm{m}}: 200 \mu \mathrm{H}$; transformer turns ratio $n: 4$.

Fig. 7 shows the required deadtime for LLC resonant converter primary switch in different operation regions. Clearly, the required deadtime varies with the load in both below resonant frequency and above resonant frequency operation regions. In particular, in above resonant frequency operation region, under light load condition, the required deadtime is extremely large, which is about five times larger than the heavy load condition. Therefore, an adaptive deadtime strategy is of

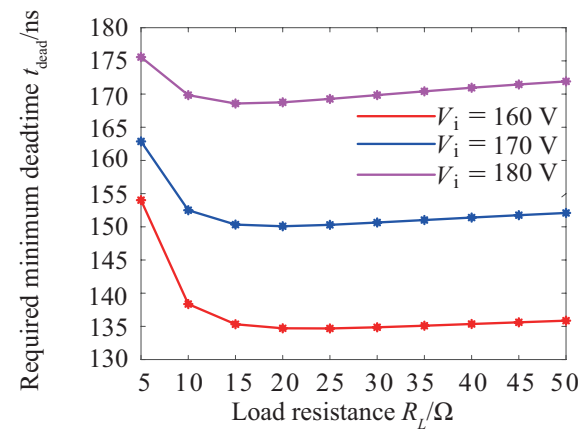

(a) Below resonant frequency operation

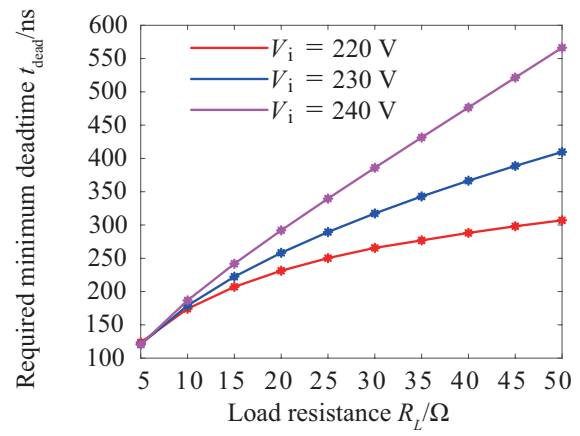

(b) Above resonant frequency operation



(c) At resonant frequency operation

Fig. 7. Required deadtime for LLC converter in different operation regions with different output power and input voltage.

great importance to improve the converter efficiency for LLC resonant converter. Otherwise, a fixed large deadtime will lead to efficiency degradation under heavy load operation conditions. If the deadtime is designed based on the heavy load condition, then the ZVS operation under some conditions cannot be achieved, which will generate electro-magnetic interference (EMI) noise. The main reason is that the ZVS analysis for LLC resonant converter is determined by the switch turn-off current, in below or above resonant frequency region, the primary switch turn-off current is related with the converter output power. In contrast, at resonant frequency operation, the converter deadtime almost remains unchanged under different load conditions since the voltage across the magnetizing inductance is always clamped by the output voltage so that the magnetizing inductor current during deadtime can be viewed as constant for different load conditions. Therefore, another advantage for the DCXs is the simplified deadtime control strategy. 


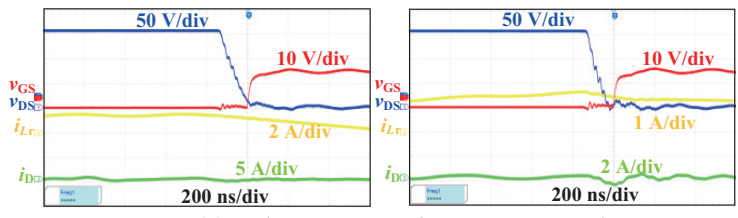

(a) Below resonant frequency operation

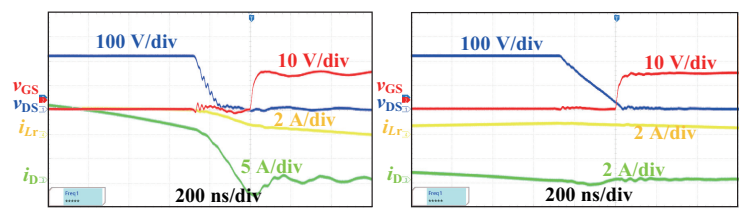

(b) Above resonant frequency operation

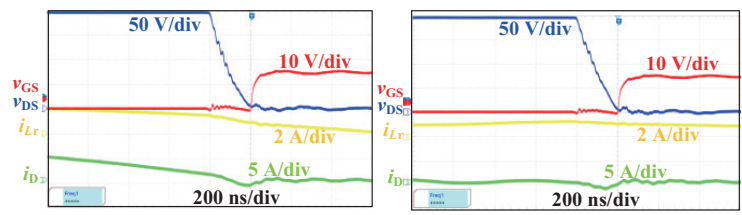

(c) At resonant frequency operation

Fig. 8. ZVS operation experiment waveforms in different operation regions. Ch1: Gate source voltage $V_{\mathrm{GS}} ; \mathrm{Ch} 2$ : Drain-to-source voltage $V_{\mathrm{DS}} ; \mathrm{Ch} 3$ : Secondary rectifier diode current $i_{\mathrm{D}} ; \mathrm{Ch} 4$ : Resonant inductor current $i_{\mathrm{Lr}}$

Fig. 8 shows the experiment waveforms with the same circuit parameters in different operation regions. Please note that the left figures are tested when the load resistance equals 5 $\Omega$, while the right figures are tested when the load resistance equals $50 \Omega$. Fig. 8(a) shows the experiment waveforms when input voltage equals $160 \mathrm{~V}$ and the LLC converter is operating in below resonant frequency region with a deadtime of $160 \mathrm{~ns}$. The ZVS operation under light load condition is easier to be achieved when compared with heavy load condition. Fig. 8(b) shows the experiment waveforms when input voltage equals $220 \mathrm{~V}$ and the LLC converter is operating in above resonant frequency region with a deadtime of $310 \mathrm{~ns}$. The ZVS operation is much easier to be achieved under heavy load condition when compared with light load condition. Fig. 8(c) shows the experiment waveforms when input voltage equals $200 \mathrm{~V}$ and the LLC converter is operating at resonant frequency point with a deadtime of $210 \mathrm{~ns}$. Clearly, the ZVS operation under different conditions are almost same. Therefore, a fixed deadtime control strategy can be applied, which simplifies system control and improve operation reliability.

\section{E. Control Stability for Different Operation Regions}

Another big concern for the conventional frequency-controlled resonant converters is the control stability issue in both below and above resonant frequency operation regions. The FHA circuit model in Fig. 4 can be modified as shown in Fig. 9(a) by taking the circuit parasitic capacitors into consideration. Please note that these parasitic capacitors mainly include the transformer stray capacitor and secondary rectifier junction capacitor.

According to Kirchhoff voltage law (KVL), the output voltage of the resonant converter is proportional with (3).

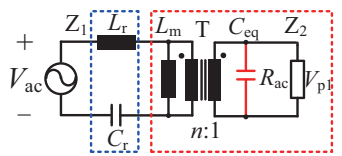

(a) Modified FHA model by taking parasitic capacitors into consideration

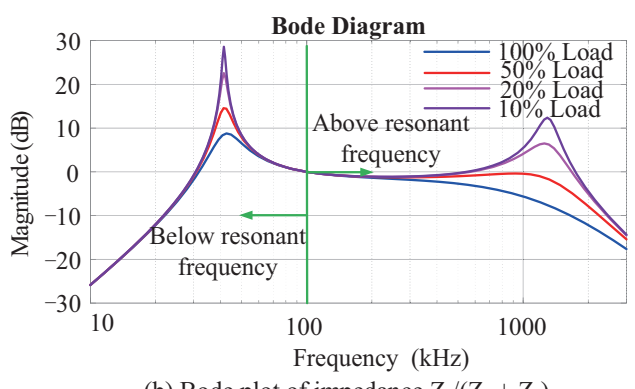

(b) Bode plot of impedance $Z_{2} /\left(Z_{1}+Z_{2}\right)$

Fig. 9. Control instability issues for conventional frequency-controlled resonant converter.

$$
\frac{\mathrm{Z}_{2}}{\mathrm{Z}_{1}+\mathrm{Z}_{2}} V_{\mathrm{ac}}=V_{\mathrm{p} 1}
$$

The bode plot for impedance $Z_{2} /\left(Z_{1}+Z_{2}\right)$ is plotted to demonstrate the influence of the parasitic capacitor on LLC converter operation. The circuit parameters are listed as follows: $C_{\mathrm{r}}=35.2 \mathrm{nF}$, $L_{\mathrm{r}}=72 \mu \mathrm{H}, L_{\mathrm{m}}=346 \mu \mathrm{H}, N=3.8$. The full load resistance is $R_{L}=10 \Omega$. The equivalent parasitic capacitance $C_{\mathrm{eq}}=500 \mathrm{pF}$ is selected. According to the above circuit parameters, Fig. 9(b) shows the bode plot of impedance $Z_{2} /\left(Z_{1}+Z_{2}\right)$ under different load conditions. In below resonant frequency operation region, the control instability issue occurs when the converter operating switching frequency is around the peak gain frequency. At the peak operation point, the slope of the voltage gain curve is reversed. In above resonant frequency region, due to the existence of the parasitic capacitor, instead of decreasing, the voltage gain increases with the increase of switching frequency, which will cause control instability issue. Therefore, the resonant converter circuit parameters have to be carefully designed to avoid these control instability issues. In contrast, the DC transformer operation can avoid these control instability issues and simplify the converter design significantly.

Moreover, with the resonant frequency operation, the wide switching frequency operation associated with conventional frequency-controlled LLC resonant converter is mitigated, which is beneficial for the optimization and design of converter EMI filter, resonant inductor, transformer, and gate driver circuitry.

\section{OverVIEW OF IsSUES AND SOlutions FOR RESONANT Converter Based DCXs}

Although the resonant converters based DCXs have been widely adopted in numerous industrial applications, there are two major issues associated with DCXs in practical applications. The first one is the regulation capability of DCXs, and the second one is the circuit components variations or automatic resonant frequency tracking capability. In this section, these two issues and the existing solutions are reviewed. 


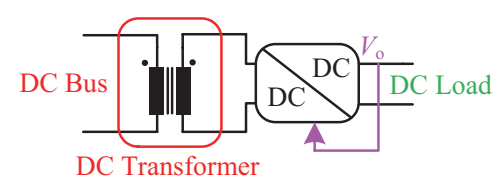

(a) DCX performing as first stage in DC/DC system

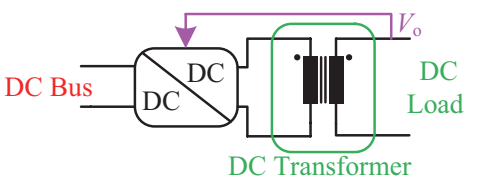

(b) DCX performing as second stage in DC/DC system

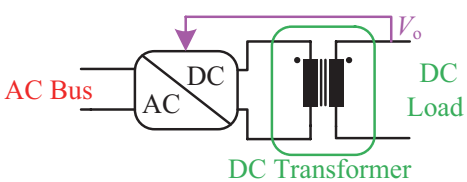

(c) DCX performing as second stage in AC/DC system

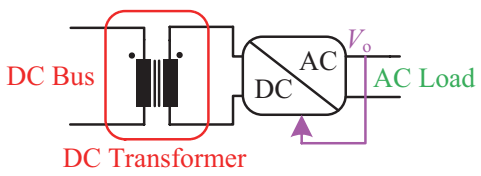

(d) DCX performing as first stage in DC/AC system

Fig. 10. Block diagrams for two-stage based DCXs.

\section{A. Regulation Capability of DCXs}

At resonant frequency operating point, the regulation capability for the resonant converter is lost. Based on the existing literature, there are mainly two approaches to achieve the output voltage regulation for DCXs: 1) two-stage solution or cascaded structure; 2) partial power processing solution.

\section{1) Two-stage Solution}

Fig. 10 shows the block diagrams for the two-stage based DCXs. Clearly, the system output voltage is regulated by the other $\mathrm{DC} / \mathrm{DC}, \mathrm{AC} / \mathrm{DC}$, or DC/AC converter. The main disadvantages for the two-stage based DCXs are that more components are required and the system efficiency is degraded due to the cascaded connection of DCX and the additional power converter. On the other hand, due to the cascaded connection of two converters, a large step-up or step-down voltage conversion ratio can be easily achieved.

Table I has summarized the existing two-stage solutions for DCXs with regulation capability, including topologies and applications. For the DCX based two-stage systems, the conventional pulse width modulation (PWM) converters, like Buck, Boost, Buck-boost, and SEPIC, can be adopted as either the front stage or second stage to achieve the output voltage regulation. The selection of these PWM converters is based on the applications. Generally, Buck converter is selected for the step-down applications, while Boost converter is selected for the step-up applications. Buck-boost and SEPIC converters are adopted in the applications require to both step-up and step-down the input voltage. The difference is that the output voltage of Buck-boost is inverting, while the output voltage

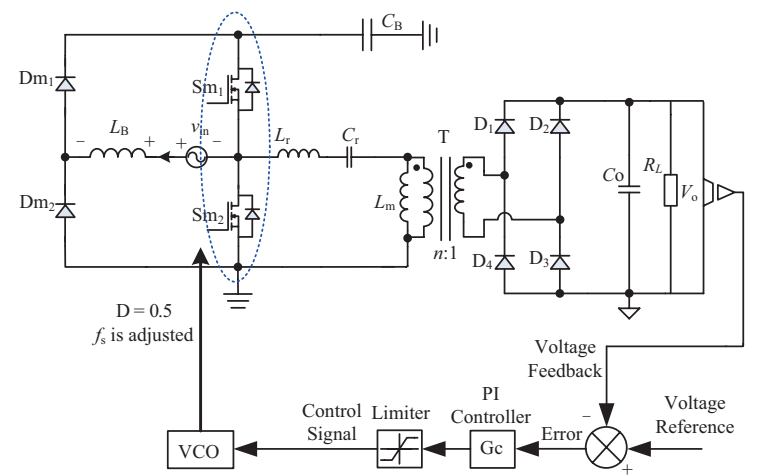

(a) Single-stage LLC converter with frequency control [24], [25]



(b) Single-stage LLC converter with magnetic control [26]

Fig. 11. Control diagram for single-stage LLC converter with different control strategies.

for SEPIC is noninverting. These PWM converters based twostage systems are simple and easy to be analyzed. For the AC/ DC applications, like on-board battery charger, laptop adaptor, and lighting emitter diode (LED) driver, the regulation capability is achieved on the front power factor correction circuit (PFC) stage, where the variable DC-link voltage control strategy is usually adopted. The traditional Boost PFC is normally adopted in these applications. Other types of PFCs, like Buck PFC, SEPIC PFC, Buck-boost PFC, can also be adopted based on the input voltage and output voltage range. For the high step-down applications, like server power supplies, the LLC resonant converter based DCX stage is normally put as the first stage to achieve bus voltage step-down from either $380 \mathrm{~V}$ to $48 \mathrm{~V}$ or $48 \mathrm{~V}$ to $12 \mathrm{~V}$, then, a second stage, point of load (POL) converter is used to provide constant output voltage levels, like $3.3 \mathrm{~V}$ and $5 \mathrm{~V}$. Generally, the Buck converter or multi-phase Buck converter is adopted as the POL converter. Thus, the regulation capability is achieved on the second stage. For the high step-up applications, like fuel cell and photovoltaic (PV) systems, the Boost converter is acting as the first stage, and the DCX is performing as the second stage. The regulation capability is achieved by the Boost converter stage. The maximum power point tracking (MPPT) is also achieved in the Boost converter stage and that is the main reason that the DCX is put as the second stage.

Although the two-stage solution can achieve output voltage regulation for DCXs, the system efficiency is degraded due to 
TABLE I

Existing Two-Stage Solution for Resonant Converter Based DCX With Regulation Capability

\begin{tabular}{|c|c|c|c|c|c|c|c|}
\hline Ref & Topology & Application & Control & Input voltage & $\begin{array}{l}\text { Output } \\
\text { voltage }\end{array}$ & $\begin{array}{l}\text { DCX transformer } \\
\text { turns ratio }\end{array}$ & $\begin{array}{l}\text { Maximum } \\
\text { step-down or } \\
\text { step-up } \\
\text { voltage ratio }\end{array}$ \\
\hline$[21]$ & Boost PFC+FBLLC & On-board battery charger & PWM & - & - & $1: 1$ & - \\
\hline$[22]$ & Boost PFC+HBLLC & Server power supply & PWM & - & - & $1: 1$ & \\
\hline$[35]$ & SEPIC PFC+FBLLC & On-board battery charger & PWM & - & - & $1: 1$ & - \\
\hline$[26]$ & $\begin{array}{c}\text { Integrated Totem-pole } \\
\text { bridgeless Boost PFC+HBLLC }\end{array}$ & $\begin{array}{l}\text { Low power } \mathrm{AC} / \mathrm{DC} \\
\text { power conversion }\end{array}$ & $\begin{array}{l}\text { Magnetic } \\
\text { control }\end{array}$ & - & - & $3.75: 1$ & - \\
\hline$[37]$ & $\begin{array}{c}\text { Interleaved Totem-pole } \\
\text { bridgeless Boost } \\
\text { PFC+HBCLLC }\end{array}$ & $\begin{array}{l}\mathrm{AC} / \mathrm{DC} \text { power } \\
\text { conversion }\end{array}$ & PWM & - & - & $20: 14$ & - \\
\hline $\begin{array}{l}{[6],[38],} \\
{[39]}\end{array}$ & $\begin{array}{l}\text { Bi-directional interlinking } \\
\text { converter }(\mathrm{BIC})+\text { Bi-directional } \\
\text { resonant } \mathrm{DC} \text { transformer } \\
(\mathrm{BRDT})\end{array}$ & $\begin{array}{l}\text { Hybrid AC/DC } \\
\text { microgrid }\end{array}$ & PWM & - & - & - & - \\
\hline$[8]$ & $\begin{array}{l}\text { Three-port CLLC+Three-port } \\
\text { bi-directional inverter/rectifier }\end{array}$ & $\begin{array}{l}\text { Bi-directional AC/DC } \\
\text { application }\end{array}$ & PWM & - & - & $0.9: 1$ & - \\
\hline$[40]$ & $\begin{array}{c}\text { Dual output rectifier } \\
\text { (DOR)+Dual input DCX }\end{array}$ & $\begin{array}{l}\text { Single phase } \mathrm{AC} / \mathrm{DC} \\
\text { power conversion }\end{array}$ & PWM & - & - & $1.2: 1$ & \\
\hline$[41]$ & Cascaded H-bridge+FBLLC & $\begin{array}{l}\text { AC/DC power } \\
\text { conversion }\end{array}$ & PWM & - & - & $3.5: 1$ & \\
\hline$[42],[43]$ & $\mathrm{FBLLC}+\mathrm{POL}$ & Server power supply & PWM & $60 \mathrm{~V}-85 \mathrm{~V}$ & $3.3 \mathrm{~V}$ & $10: 1$ & \\
\hline$[44]-[46]$ & FBLLC +Multi-phase Buck & Server power supply & PWM & $40 \mathrm{~V}-60 \mathrm{~V}$ & $1.7 \mathrm{~V}$ & $8: 1$ & \\
\hline$[47]$ & Buck+DCX & High step down & PWM & $36 \mathrm{~V}-75 \mathrm{~V}$ & $3.3 \mathrm{~V}$ & $7.78: 1$ & \\
\hline$[48]$ & $\begin{array}{l}\text { Bi-directional CLLC+ } \\
\text { Interleaved SR Buck }\end{array}$ & $\begin{array}{l}\text { Residential energy } \\
\text { storage system }\end{array}$ & PWM & 380 & $35 \mathrm{~V}-50 \mathrm{~V}$ & $3: 1$ & \\
\hline$[50],[51]$ & $\begin{array}{c}\text { Boost }+ \text { FBLLC }+ \text { Three phase } \\
\text { inverter }\end{array}$ & $\begin{array}{l}\mathrm{DC} / \mathrm{AC} \text { traction drive } \\
\text { application with wide } \\
\text { input voltage range }\end{array}$ & PWM & $\begin{array}{c}1000 \mathrm{~V}-2000 \\
\mathrm{~V}\end{array}$ & $700 \mathrm{~V}$ & $1: 1$ & \\
\hline$[52]$ & Boost+HBLLC & $\begin{array}{c}\text { Fuel cell with wide input } \\
\text { voltage range }\end{array}$ & PWM & $24 \mathrm{~V}-48 \mathrm{~V}$ & $400 \mathrm{~V}$ & $1: 11$ & \\
\hline$[53]$ & Buck-boost+FBLLC & $\begin{array}{l}\text { Wide input voltage range } \\
\text { application }\end{array}$ & PWM & $200 \mathrm{~V}-450 \mathrm{~V}$ & $14 \mathrm{~V}$ & $13: 1$ & \\
\hline$[54]$ & Two-phase Buck+HBLLC & $\begin{array}{l}\text { Railways applications with } \\
\text { wide input voltage range }\end{array}$ & PWM & $64 \mathrm{~V}-160 \mathrm{~V}$ & $24 \mathrm{~V}$ & $1: 1$ & \\
\hline$[55]$ & Buck+FBLLC & Server power supply & PWM & $40 \mathrm{~V}-60 \mathrm{~V}$ & $12 \mathrm{~V}$ & $\begin{array}{l}\text { 3:1(three integrated } \\
\text { transformer with turns } \\
\text { ratio of } 1 \text { for each) }\end{array}$ & \\
\hline$[56]$ & Inverting Buck-boost+HBLLC & $\begin{array}{l}\text { Low voltage DC/DC con- } \\
\text { verters for electric vehicle }\end{array}$ & PWM & $260 \mathrm{~V}-400 \mathrm{~V}$ & $14 \mathrm{~V}$ & $16: 1$ & $\approx 29$ \\
\hline$[57]$ & Three-level Buck+HBLLC & $\begin{array}{l}\text { Wide input voltage range } \\
\text { application }\end{array}$ & PWM & $160 \mathrm{~V}-300 \mathrm{~V}$ & $12 \mathrm{~V}$ & $4: 1$ & 25 \\
\hline$[10]$ & $\begin{array}{c}\text { Bi-directional } \\
\text { CLLC+Interleaved SR Buck }\end{array}$ & $\begin{array}{l}\text { Residential energy } \\
\text { storage systems }\end{array}$ & PWM & $400 \mathrm{~V}$ & $50 \mathrm{~V}-35 \mathrm{~V}$ & $3: 1$ & $\approx 12$ \\
\hline
\end{tabular}

the two-stage power conversion. To reduce the power conversion stages or circuit components, the quasi-single stage or integrated two-stage solutions are proposed, which are preferred in low and medium power applications. However, in some topologies, the DCX operation of LLC stage is not maintained. For example, in [24] and [25], for these traditional single-stage LLC converters with frequency control, the LLC stage operating switching frequency is variable and not constant at resonant frequency. Therefore, the LLC converter is not operating as DCX with constant voltage gain. The system control diagram is shown in Fig. 11(a). To achieve DCX operation for LLC stage, the magnetic control is proposed for the single-stage LLC converter in [26] as shown in Fig. 11(b), where the fixed switching frequency operation at resonant frequency and constant duty cycle of 0.5 are achieved for the primary switch so that the LLC stage is operating as DCX. The output voltage 


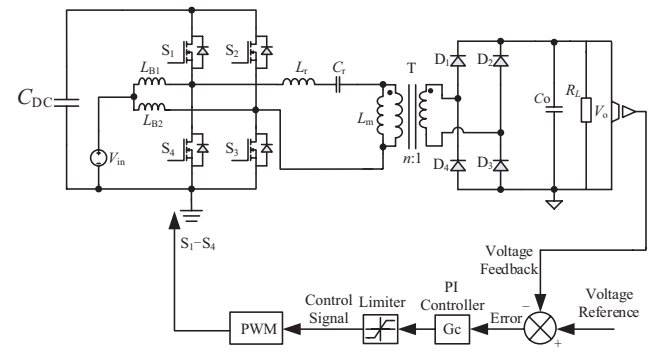

(a) Control diagram for the proposed interleaved boost-integrated LLC resonant converter in [27]

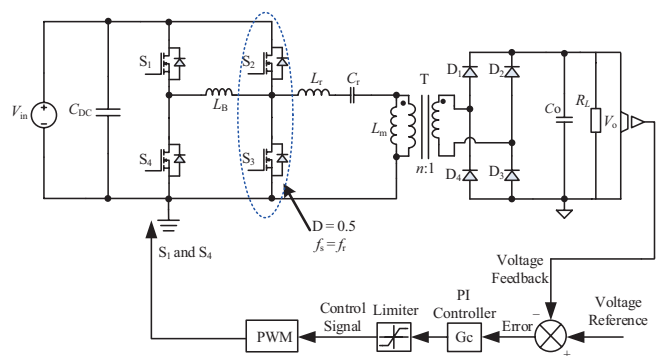

(b) Control diagram for the proposed buck -boost integrated LLC resonant converter in [28]

Fig. 12. Control diagram for integrated LLC converter with different control strategies.

regulation is achieved by adjusting the Boost inductance value with variable inductor control. Another important characteristic is that the dc-link voltage remains almost constant for the proposed quasi-single stage converter, which simplifies the dc-link capacitor design and optimization when compared with the variable dc-link voltage solution.

In [27], the integrated two-phase Boost converter and fullbridge LLC (FBLLC) converter topology is proposed and the circuit topology is shown in Fig. 12(a). Although the LLC converter switching frequency equals to its resonant frequency, due to the PWM control on the full-bridge switches, the duty ratio for the full-bridge LLC converter is no longer constant at 0.5 . Therefore, for the topology proposed in [27], the high efficiency operation characteristic of DCX is lost. On the contrary, for the proposed integrated Buck-boost and half-bridge LLC converter in [28], the PWM control is applied on the Buckboost switches as shown in Fig. 12(b), and the phase shift angle between two half-bridge is controlled to regulate the inductor current waveform, so the duty ratio and switching frequency for half-bridge LLC converter keep constant. Therefore, the high efficiency operation characteristic for DCX still remained.

Another important issue associated with two-stage solutions is the system stability. The DCX itself does not have stability problem since it is operating in open-loop with fixed switching frequency and duty cycle. Even if the DCX and the converter in another stage can operate stably individually, by connecting these two converters in cascaded form, the system instability issue may occur due to the interactions between two converters impedances. As same as the traditional two-stage system, in order to avoid system instability, based on the Middlebrooks's theory, the output impedance of the first-stage converter should be always smaller than the input impedance of the second-stage

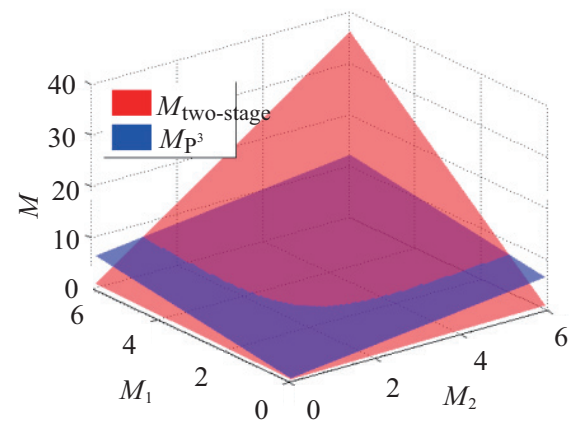

(a) System voltage gain comparison

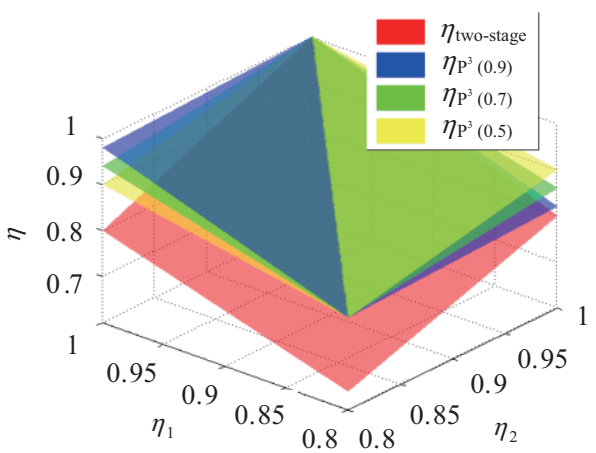

(b) System efficiency comparison

Fig. 13. System voltage gain and efficiency comparisons between two-stage solution and partial power processing solution.

converter. The stability analysis and modelling of LLC/CLLC converter can be found in [29]-[33]. Therefore, the system stability should be examined when designing the two-stage system.

\section{2) Partial Power Processing $\left(P^{3}\right)$ Solution}

The main disadvantage for the two-stage solution is that the system efficiency is the product of each stage, to improve the system conversion efficiency, the partial power processing solution is proposed. Comparisons between the two-stage solution and partial power processing solution are made from the voltage gain and efficiency perspectives. The voltage gain and efficiency for the two-stage solution can be simply expressed as the products of two units.

$$
\begin{gathered}
M_{\text {two-stage }}=M_{1} M_{2} \\
\eta_{\text {two-stage }}=\eta_{1} \eta_{2}
\end{gathered}
$$

For the partial power processing structure, the system voltage gain and efficiency can be expressed as the sum of two individual units.

$$
\begin{gathered}
M_{\mathrm{P}^{3}}=M_{1}+M_{2} \\
\eta_{\mathrm{P}^{3}}=\frac{P_{\mathrm{o} 1}+P_{\mathrm{o} 2}}{P_{\text {in } 1}+P_{\text {in } 2}}=\eta_{1} \frac{P_{\mathrm{in} 1}}{P_{\mathrm{in}}}+\eta_{2} \frac{P_{\mathrm{in} 2}}{P_{\mathrm{in}}}
\end{gathered}
$$

Fig. 13(a) shows the converter voltage gain comparison re- 


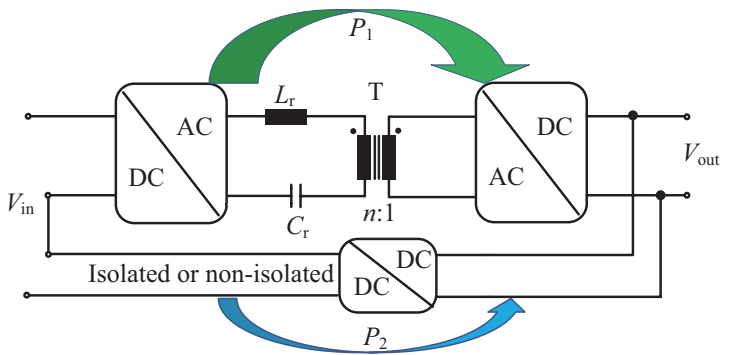

(a) Input series and output parallel type

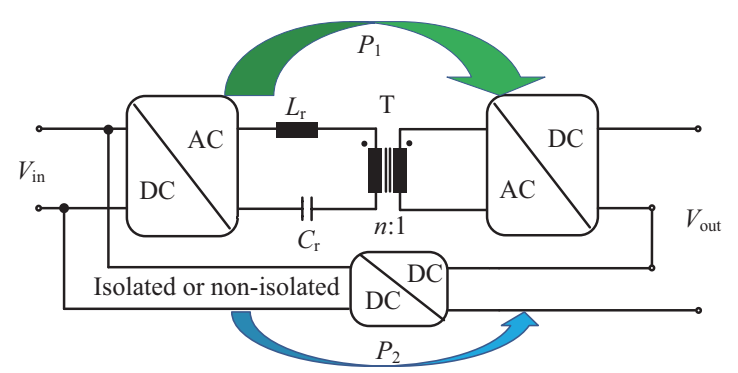

(b) Input parallel and output series type

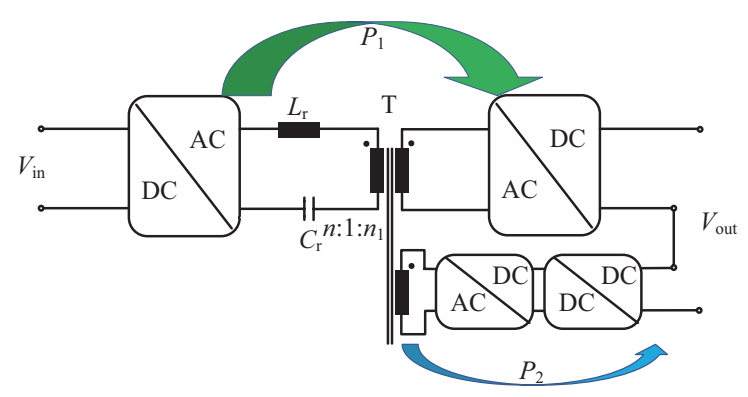

(c) Output series with integrated transformer type

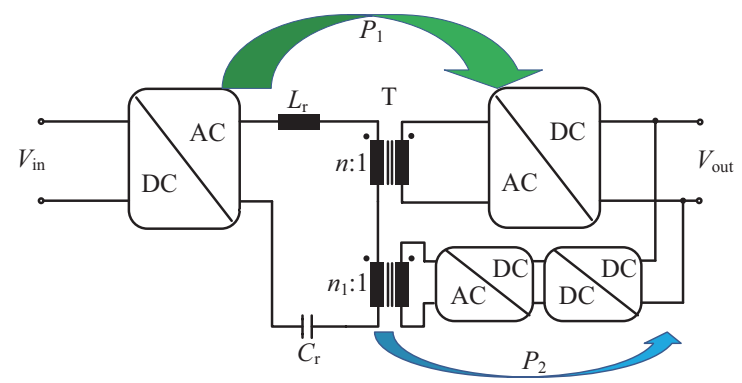

(d) Output parallel with separate transformer type

Fig. 14. Circuit diagram for different types of partial power processing converters.

sults between the two-stage solution and partial power processing solution. Clearly, the two-stage solution is much preferred in applications where a very large or very small voltage gain ratio is required, like the high step-down server power supplies. Fig. 13(b) shows the system efficiency comparison between these two solutions, where the individual converter efficiency is assumed to be in the range of $[0.8,1] .0 .9,0.7$, and 0.5 represents the power ratio between these two individual converters in the partial power processing solution. Clearly, the system efficiency for partial power processing is higher than the twostage solution. In addition, with the increase of the power ratio, the converter efficiency is increased. Therefore, when designing the partial power processing converter, the high efficiency unit DCX should be designed to handle as much as possible of the output power to improve the system efficiency.

The circuit diagrams for different types of partial power processing converter are summarized in Fig. 14. Based on the system requirements, different types of partial power processing converters can be adopted. For Fig. 14(a) or the ISOP structure, due to the series connection of input voltage, the voltage stress on the primary side of each converter unit is reduced. Meanwhile, the voltage gain requirement on each unit can be reduced. Therefore, the ISOP structure is advantageous in high input voltage and step down applications to relieve the voltage stress on the primary semiconductors and relieve the voltage gain requirement on the DCX stage. However, system integration or components sharing for two converter units is not available, which makes it less attractive in low power applications. For Fig. 14(b) or the IPOS structure, it is advantageous in high output voltage or step-up applications due to its series connection of two outputs. Low voltage stress and voltage gain requirement can be achieved for the DCX stage. Moreover, system integrations can be achieved to some extent by sharing part of the DC/AC inverter. For Fig. 14(c), similarly, due to the series connection of two outputs, the voltage stress and voltage gain requirement on the DCX stage is reduced so that it is advantageous in high output voltage and step-up applications. Moreover, the isolation capability for the auxiliary converter is also ensured so that the output is completely isolated from the input. Only one transformer is required for this structure, which can simplify the converter circuit complexity and improve power density. In addition, the primary side is shared between two converter units. But the difficulty of transformer design is also increased for this multi-winding structure. For Fig. 14(d), it is more advantageous in high input voltage and step down applications. Completely isolation between the output side and input side is achieved. The primary circuit is shared with the DCX stage. However, two transformers are still required. Generally, input series connection is preferred for high input voltage and step-down applications, while output series is advantageous in high output voltage or step-up applications.

Table II summarizes the existing partial power processing converters with DCXs. In Fig. 14(a) and Fig. 14(b), if non-isolated PWM converters are adopted, then the system is only partial isolated. The minimum power ratio is obtained by calculating the power ratio between DCX and auxiliary converter under the worst operation condition.

In order to reduce the converter components and cost, some components can be shared between the DCX and auxiliary converter. For example, the transformer secondary rectifier is shared between the LLC resonant converter and dual-active-bridge (DAB) converter in [6] and the phase shift modulation (PSM) is applied on the DAB converter to regulate the system output voltage. The primary switch of two LLC units are shared in [66]-[68]. In addition, with the multi-winding transformer and separate transformer solution, the primary DC/ AC power conversion circuit of the converter can be removed. Generally, compared with the two-stage solution, the maxi- 
TABLE II

Existing Partial Power Processing Solution for Resonant Converter Based DCX With Regulation Capability

\begin{tabular}{|c|c|c|c|c|c|c|c|c|c|c|}
\hline Ref & Type & Topology & Application & Control & Isolation & Input voltage & $\begin{array}{l}\text { Output } \\
\text { voltage }\end{array}$ & $\begin{array}{l}\text { Minimum } \\
\text { power } \\
\text { ratio }\end{array}$ & $\begin{array}{c}\text { DCX } \\
\text { transformer } \\
\text { turns ratio }\end{array}$ & $\begin{array}{c}\text { Maximum } \\
\text { step-up or } \\
\text { step-down } \\
\text { ratio }\end{array}$ \\
\hline [58], [59] & (a) & Buck+FBLLC & Server power supply & PWM & $\begin{array}{l}\text { Partial } \\
\text { isolated }\end{array}$ & $42 \mathrm{~V}-55 \mathrm{~V}$ & $1 \mathrm{~V}$ & $73 \%$ & $\begin{array}{c}40: 1 \\
\text { (Integrated } \\
\text { matrix } \\
\text { transformer) }\end{array}$ & 55 \\
\hline [60] & (a) & $\begin{array}{l}\text { Buck-boost+Two } \\
\text { HBLLC }\end{array}$ & Server power supply & PWM & $\begin{array}{l}\text { Fully } \\
\text { isolated }\end{array}$ & $32 \mathrm{~V}-75 \mathrm{~V}$ & $5 \mathrm{~V}$ & $40 \%$ & $3: 1$ & 25 \\
\hline [61] & (a) & HBLLC+HBLLC & Server power supply & PFM & $\begin{array}{l}\text { Fully } \\
\text { isolated }\end{array}$ & $36 \mathrm{~V}-60 \mathrm{~V}$ & $12 \mathrm{~V}$ & $50 \%$ & $1: 2$ & 5 \\
\hline [62] & (b) & $\begin{array}{c}\text { HBLLC }+ \text { Non-inverting } \\
\text { Buck-boost }\end{array}$ & $\begin{array}{l}\text { PV step-up } \\
\text { application }\end{array}$ & PWM & $\begin{array}{l}\text { Partial } \\
\text { isolated }\end{array}$ & $40 \mathrm{~V}-60 \mathrm{~V}$ & $400 \mathrm{~V}$ & $67.5 \%$ & $1: 6.75$ & 10 \\
\hline [63] & (b) & HBLLC+FBPS & $\begin{array}{l}\text { PV step-up } \\
\text { application }\end{array}$ & PSM & $\begin{array}{l}\text { Fully } \\
\text { isolated }\end{array}$ & $40 \mathrm{~V}-60 \mathrm{~V}$ & $380 \mathrm{~V}$ & $63 \%$ & 1:6 & 9.5 \\
\hline$[64],[65]$ & (b) & FBLLC+DAB & Step-down application & PSM & $\begin{array}{l}\text { Fully } \\
\text { isolated }\end{array}$ & $350 \mathrm{~V}$ & $48 \mathrm{~V}$ & $80 \%$ & $5.8: 1$ & $\approx 7.3$ \\
\hline [66], [67] & (b) & HBLLC+HBLLC & $\begin{array}{l}\text { On-board battery } \\
\text { charger }\end{array}$ & $\begin{array}{l}\text { Magnetic } \\
\text { control }\end{array}$ & $\begin{array}{l}\text { Fully } \\
\text { isolated }\end{array}$ & $340 \mathrm{~V}-380 \mathrm{~V}$ & $\begin{array}{l}120 \mathrm{~V} \\
-160 \mathrm{~V}\end{array}$ & $55.9 \%$ & $1.9: 1$ & $\approx 3.17$ \\
\hline [68] & (b) & FBLLC+FBLLC & $\begin{array}{l}\text { On-board battery } \\
\text { charger }\end{array}$ & PFM & $\begin{array}{c}\text { Fully } \\
\text { isolated }\end{array}$ & $380 \mathrm{~V}-420 \mathrm{~V}$ & $\begin{array}{l}250 \mathrm{~V} \\
-420 \mathrm{~V}\end{array}$ & $50 \%$ & $1.82: 1$ & 1.68 \\
\hline [69] & (c) & FBLLC+Buck & Battery charger & PWM & $\begin{array}{l}\text { Fully } \\
\text { isolated }\end{array}$ & $400 \mathrm{~V}$ & $\begin{array}{l}200 \mathrm{~V} \\
-420 \mathrm{~V}\end{array}$ & $35.7 \%$ & $2.6: 1$ & 2 \\
\hline$[70],[71]$ & (d) & HBLLC+Buck & Server power supply & PWM & $\begin{array}{c}\text { Fully } \\
\text { isolated }\end{array}$ & $360 \mathrm{~V}$ & $40 \mathrm{~V}$ & $88.9 \%$ & $4: 1$ & 9 \\
\hline
\end{tabular}

mum step-down or step-up ratio is smaller. Nevertheless, the integrated matrix transformer technique discussed in [58], [59] can be adopted to achieve high voltage conversion ratio.

\section{B. Automatic Resonant Frequency Tracking}

Although the best efficiency operating point is designed for the resonant converter, during the real application, the resonant circuit components values are not constant. In reality, the resonant inductor and resonant capacitor values will vary with circuit operating conditions, like voltage, current, and temperature. In addition, the aging effect will also make the components values variable. Once the components values variations occur, the optimal efficiency operation for the DCX is lost since the switching frequency does not equal to the resonant frequency anymore. In particular, for the systems with a regulated bus voltage and DCX is used to connect to the load, the output voltage will not be regulated since the voltage gain for DCX is not unity anymore. Therefore, the automatic resonant frequency tracking is critical for resonant converters based DCXs.

The existing automatic resonant frequency tracking techniques are briefly introduced based on the operational principles of LLC resonant converter. Fig. 6 shows the typical operation waveforms for the LLC resonant converter operating in below resonant frequency operation, at resonant frequency operation, and above resonant frequency operation. We can find that in below resonant frequency operation, there is a small period that the secondary rectifier current decreases to zero and stay at zero in half of the switching cycle. Thus, the zero current duration time is detected and compensated in [72] to achieve automatic resonant frequency tracking. The fatal defect for this technique is that it fails to achieve the resonant frequency tracking in above resonant frequency operation region since the secondary rectifier current is operating in continuous conduction mode.

For LLC resonant converter with synchronous rectification (SR), at resonant frequency operation, there would be no body diode conduction period for the SR MOSFET. Based on the duty ratio difference between the primary switch and SR MOSFET, the switching frequency can be adjusted accordingly to achieve resonant frequency tracking [73], [74]. For example, in below resonant frequency operation, the SR MOSFET has a smaller duty ratio when compared with the primary switch since the SR MOSFET turns off earlier, then, the primary switch switching frequency is increased to mitigate the duty ratio difference. Although this technique can achieve resonant frequency tracking in both below and above resonant frequency operation regions, the earlier turn-on issue for the SR MOSFET cannot be ignored when the switching frequency is far away from the resonant frequency. In addition, this technique can only be applied for LLC resonant converters with synchronous rectification. A high speed digital controller is required to achieve the duty ratio difference calculation and step-by-step adjustment.

Another indicator that can be used for automatic resonant frequency tracking is the total harmonic distortion (THD) of the resonant inductor current [75]. It is clear that the current THD reaches the minimum value when it is operating at resonant frequency point. Therefore, the automatic resonant frequency tracking can be achieved by detecting and calculating the reso- 
TABLE III

Comparisons Among Different Resonant Frequency Tracking Techniques

\begin{tabular}{|c|c|c|c|c|c|c|c|c|c|}
\hline Ref & Required signals & $\begin{array}{l}\text { Below resonant } \\
\text { frequency } \\
\text { region }\end{array}$ & $\begin{array}{l}\text { Above resonant } \\
\text { frequency } \\
\text { region }\end{array}$ & $\begin{array}{l}\text { All LLC } \\
\text { topologies }\end{array}$ & $\begin{array}{l}\text { High } \\
\text { bandwidth } \\
\text { comparator }\end{array}$ & $\begin{array}{l}\text { High speed } \\
\text { digital } \\
\text { controller }\end{array}$ & Noise immunity & $\begin{array}{l}\text { Power } \\
\text { loss for } \\
\text { sampling }\end{array}$ & Cost \\
\hline$[72]$ & Secondary rectifier current & Yes & No & Yes & Yes & No & Low & High & High \\
\hline$[73],[74]$ & $\begin{array}{l}\text { Output voltage and SR } \\
\text { drain-to-source voltage }\end{array}$ & Yes & No & No & Yes & Yes & Low & Low & High \\
\hline$[75]$ & Resonant inductor current & Yes & Yes & Yes & No & Yes & Low & High & High \\
\hline$[76]$ & Resonant inductor current & Yes & Yes & Yes & Yes & Yes & Low & High & High \\
\hline$[77]-[79]$ & $\begin{array}{l}\text { Resonant tank input } \\
\text { voltage and transformer } \\
\text { primary side voltage }\end{array}$ & Yes & Yes & Yes & No & No & Low & Low & Low \\
\hline [80] & $\begin{array}{l}\text { Output voltage and } \\
\text { absolute transformer } \\
\text { secondary voltage }\end{array}$ & Yes & Yes & Yes & No & No & $\begin{array}{c}\text { High (Large } \\
\text { voltage signal) }\end{array}$ & Low & Low \\
\hline
\end{tabular}

nant inductor current THD value. However, the main disadvantage is that a high speed digital controller is required to perform the Fourier analysis for the resonant inductor current.

No matter which region the LLC resonant converter is operating in, the duration between the peak value of the inductor current and the zero-crossing point value is one fourth of the resonant switching frequency as labelled in Fig. 6. Based on this characteristic, by detecting the peak and zero-crossing points of the resonant inductor current, the resonant frequency tracking can be achieved for all operation regions [76]. Nevertheless, the main disadvantage of this technique is that complicate analog circuitries are required to achieve resonant inductor current peak and zero-crossing point detection.

The above-mentioned three techniques are based on the resonant inductor or secondary rectifier diode currents. In the following part, the circuit voltages based resonant frequency tracking techniques are introduced. As can be seen from Fig. 7, the resonant tank input voltage $V_{\mathrm{HB}}$ and the transformer secondary side voltage $v_{\text {sec }}$, it can be found out that there is no phase difference between these two voltages at resonant frequency operation. However, the phase difference exists when the LLC resonant converter operating point is different from the resonant frequency point. Based on this characteristic, a closedloop control is implemented to eliminate the phase mismatch between these two voltage signals to achieve resonant frequency tracking [77]-[79]. The main disadvantage for this method is that these two voltage signals are periodical and can be easily affected by the circuit noises.

In below resonant frequency operation, the transformer secondary side voltage is not always clamped by the output voltage as shown in Fig. 6(a) when compared with resonant frequency and above resonant frequency operation. Therefore, the absolute average value of transformer secondary side voltage is less than the output voltage in below resonant frequency operation. Based on this characteristic, the resonant frequency tracking is achieved by calculating the ratio between the absolute average transformer secondary side voltage and the output voltage [80]. In order to distinguish between the at resonant frequency operation and above resonant frequency operation, if the calculated voltage ratio equals unity, the switching fre- quency is decreased until the calculated value is less than unity, and the last step switching frequency will be the tracked resonant frequency. The advantage for this technique is that only the voltage average values are required, no high-bandwidth comparator is required. In addition, the detected signals are non-sensitive to the circuit noises. However, additional circuitry is required to detect the transformer secondary side voltage.

The comparisons among these different resonant frequency tracking techniques are summarized in Table III. Based on the comparison results, the following recommendations are made when selecting the automatic resonant frequency tracking technique: 1) if derating is the most of the case for the resonant components variations, then the secondary rectifier zero current based technique can be adopted; 2) if the system cost is not a concern, then these methods that require a high-end digital controller can be adopted [73]-[75]; 3) overall speaking, the voltage based resonant frequency tracking techniques have the advantages of low cost and low loss when compared with the current based techniques. Therefore, the voltage based resonant frequency tracking techniques [77]-[80] can be adopted in most of the applications.

\section{Components Variations Compensation From Design Point of View}

The resonant components tolerances will affect the resonant frequency operation of both LLC and CLLC resonant converters. Different from LLC resonant converter, the CLLC resonant converter can only be considered as LLC resonant converter if the resonant frequencies for both primary side and secondary side are same. However, in practice, although the resonant components values are designed same initially, due to the components tolerances and the differences of operating conditions, the resonant frequencies for primary side and secondary side may be different. Thus, the converter operating point may deviate from the resonant frequency.

For LLC resonant converter, the resonant components values variations can be compensated by using the following two techniques: 1) automatic resonant frequency tracking techniques: these techniques can automatically find the new resonant fre- 



(c) $K=15$

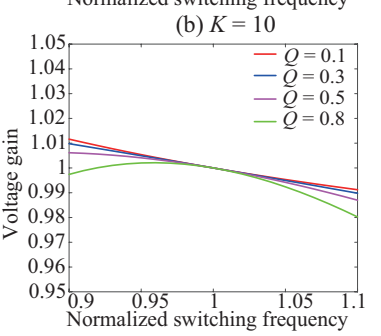

(d) $K=20$

Fig. 15. LLC converter voltage gain range with different inductor ratio values.

TABLE IV

Voltage Gain Range Comparisons Among Different Inductor Ratio VALUES FOR LLC CONVERTER

\begin{tabular}{lccc}
\hline \hline $\begin{array}{l}\text { Inductor } \\
\text { ratio } K\end{array}$ & $f_{\mathrm{n}}=0.9$ & $f_{\mathrm{n}}=1.1$ & Variation range \\
\hline$K=5$ & $0.016:[1.033$, & $0.0102:[0.9561$, & $0.0929:[0.9561$, \\
& $1.049]$ & $0.9663]$ & $1.049]$ \\
$K=10$ & $0.015:[1.009$, & $0.0108:[0.972$, & $0.0520:$ \\
& $1.024]$ & $0.9828]$ & {$[0.972,1.024]$} \\
$K=15$ & $0.015:[1.001$, & $0.0109:[0.9775$, & $0.0385:[0.9775$, \\
& $1.016]$ & $0.9884]$ & $1.016]$ \\
$K=20$ & $0.0146:[0.9974$, & $0.011:[0.9802$, & $0.0318:[0.9802$, \\
& $1.012]$ & $0.9912]$ & $1.012]$ \\
\hline \hline
\end{tabular}

quency point when there is change on the resonant components values so that the resonant frequency operation can be always maintained as we discussed in Part B of Section III; 2) another approach to mitigate the influence of resonant components variations is by selecting a large inductor ratio value $K(K$ is defined as the ratio between the magnetizing inductance and resonant inductance). The influence of the resonant components variations on the DCX can be minimized by a large $K$ design. Fig. 15 shows the converter voltage gain curves with different inductor ratio values under different load conditions when the converter switching frequency is different from the resonant frequency. Assume that there would be $10 \%$ variation of the resonant frequency caused by the resonant components tolerances. The worst cases are when the normalized switching frequency equals 0.9 and 1.1. To demonstrate the effect of large inductor ratio, the results for different inductor ratios have been summarized in Table IV. It can be seen that with a large inductor ratio, the voltage gain is more close to unity even there are variations on the resonant components values. Therefore, large inductor ratio $K$ design is an effective approach to mitigate the effects of resonant components variations. Thanks to the DCX operation, a very large inductor ratio value (larger than 20) can be selected.

Different from LLC resonant converter, CLLC resonant converter has two resonant tanks so that these automatic resonant frequency tracking techniques cannot be simply applied for the

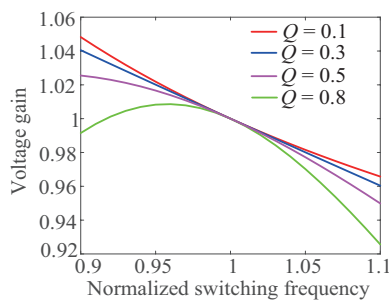

(a) $K=5$

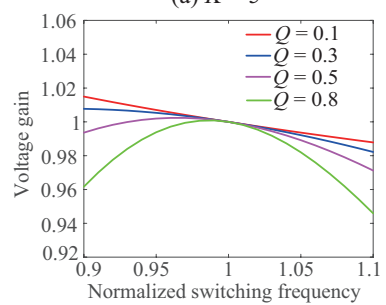

(c) $K=15$

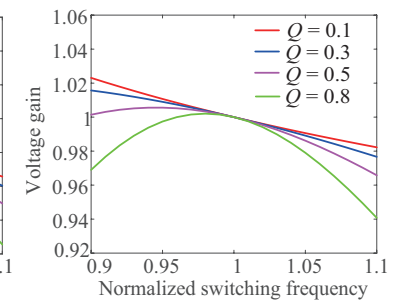

(b) $K=10$

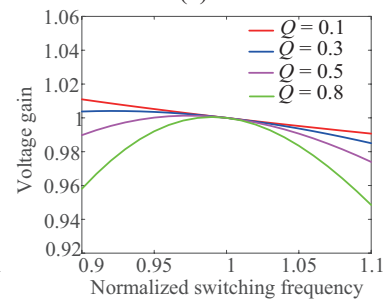

(d) $K=20$

Fig. 16. CLLC converter voltage gain range with different inductor ratio values.

TABLE V

Voltage Gain Range Comparisons Among Different Inductor Ratio VALUES FOR CLLC CONVERTER

\begin{tabular}{lccc}
\hline \hline $\begin{array}{l}\text { Inductor } \\
\text { ratio } K\end{array}$ & $f_{\mathrm{n}}=0.9$ & $f_{\mathrm{n}}=1.1$ & Variation range \\
\hline$K=5$ & $0.0565:[0.9915$, & $0.0402:[0.9256$, & $0.1224:[0.9256$, \\
& $1.048]$ & $0.9658]$ & $1.048]$ \\
$K=10$ & $0.0540:[0.969$, & $0.0415:[0.9407$, & $0.0823:[0.9407$, \\
& $1.023]$ & $0.9822]$ & $1.023]$ \\
$K=15$ & $0.0533:[0.9617$, & $0.042:[0.9459$, & $0.0691:[0.9459$, \\
& $1.015]$ & $0.9879]$ & $1.015]$ \\
$K=20$ & $0.0529:[0.9581$, & $0.0422:[0.9485$, & $0.0625:[0.9485$, \\
& $1.011]$ & $0.9907]$ & $1.011]$ \\
\hline \hline
\end{tabular}

CLLC resonant converter. Due to the resonant components tolerances, the resonant frequencies for primary side and secondary side are different, which makes it unable to track the resonant frequency and match the resonant frequency of both sides. Nevertheless, a large inductor ratio design can still be used to mitigate the effects of resonant components tolerances. Fig. 16 shows the CLLC resonant converter voltage gain performance under different quality factors and inductor ratios. Table $\mathrm{V}$ has summarized the voltage gain variation range. Clearly, with a large inductor ratio value, the converter voltage gain variation range caused by components tolerances can be mitigated. This large inductor ratio design has been analyzed and adopted for CLLC resonant converter to mitigate the resonant components variations [6], [39], and [81].

\section{System and Converter Level Design for Resonant Converter Based DCX}

In this section, the system and converter level design considerations for the resonant converter based DCX are discussed.

\section{A. System Level Design Considerations}

In order to ensure the regulation capability of the unregulated resonant converters, either two-stage or partial power 


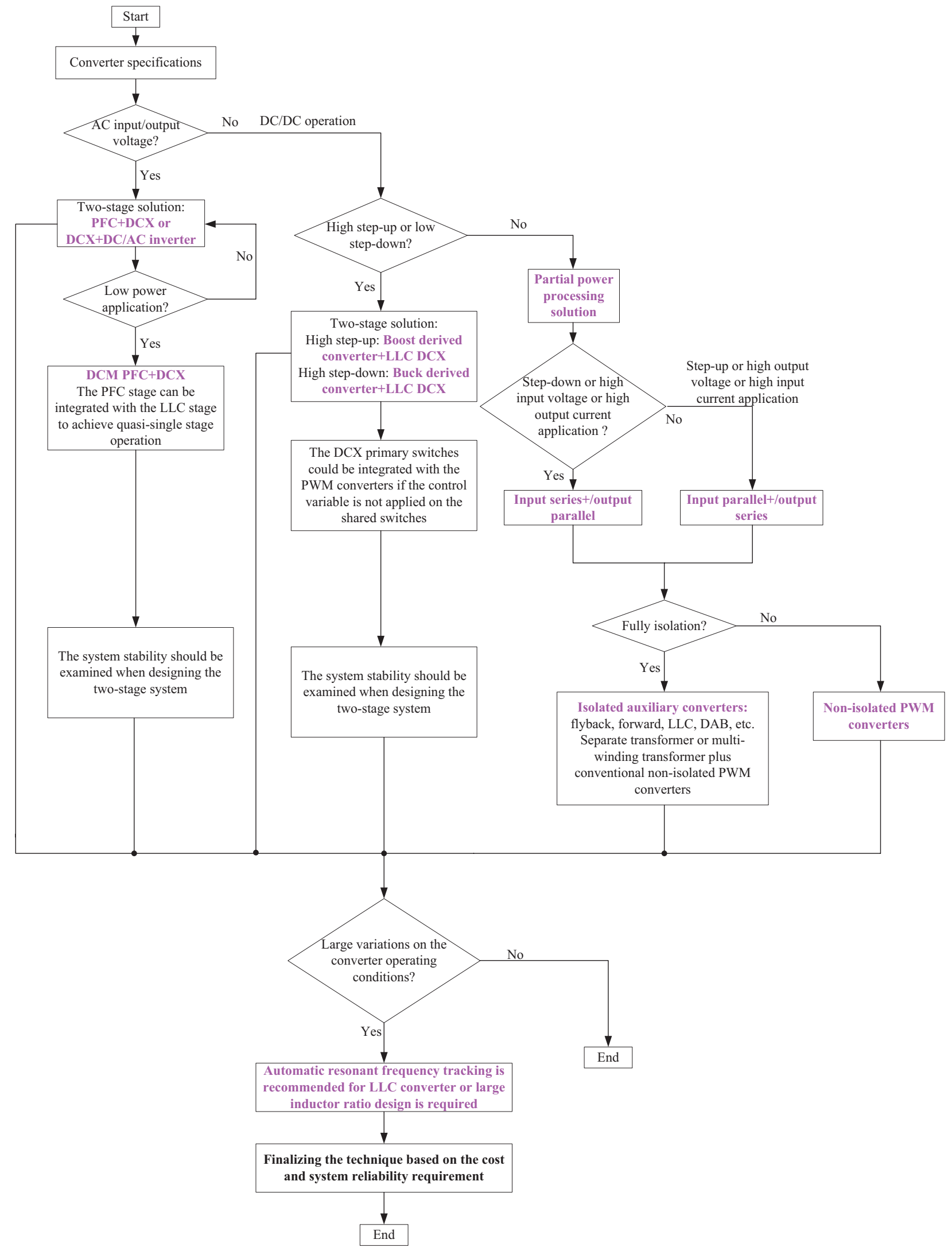

Fig. 17. System level design guidelines for resonant converters based DCXs.

processing techniques should be selected. The main design guidelines for the system level structure selection can be sum- marized as shown in Fig. 17. Please note that for the two-stage system, the system stability should be verified when designing 
the system.

For the AC/DC or DC/AC applications, the two-stage solution is required. The front stage PFC converter output voltage can be controlled to regulate the system output voltage for the $\mathrm{AC} / \mathrm{DC}$ applications. For DC/AC applications, the inverter input voltage is variable due to the unregulated resonant converters and the system output is regulated through the inverter stage. Particularly, for some low output power applications, like LED driving, the quasi-single stage solution can be used to reduce the system components and cost.

For the DC/DC applications, two-stage solution is preferred when the converter input voltage and output voltage difference is large. For example, in the data center applications, voltage regulator module (VRM) requires voltage conversion from 48 $\mathrm{V}$ to $1 \mathrm{~V}$, for these types of applications, two-stage solution is preferred since the system voltage ratio is the product of two converters and it is easy to achieve large voltage ratio. Compared with two-stage solutions, the partial power processing solutions can achieve high efficiency conversion and the efficiency performance is better if the percentage of the power handled by the DCX is large. The voltage isolation is achieved for the two-stage solutions. However, for the partial power processing solutions, the fully isolation is not ensured. If fully voltage isolation is required, the isolated converters, like flyback, forward, LLC converter, dual active bridge (DAB), can be used. In addition, the separate transformer or multi-winding transformer structure can also be used to achieve fully isolation. It is also noteworthy to mention that integrations can be made for these two power converters.

Finally, the automatic resonant frequency tracking is highly recommended for the DCX applications with wide operating conditions, like large variations on the converter output power and operating temperature. If the resonant frequency tracking is required, the specific technique can be finalized based on the converter topology, operating conditions, cost requirement, and reliability requirement.

\section{B. Converter Level Design Considerations}

Compared with frequency-controlled resonant converter, the design algorithms for unregulated resonant converter based DCXs are more simple and straightforward since the regulation capability is not required for the resonant converter. In addition, the conventional FHA based analysis method has enough accuracy to achieve the optimal design [82]. The major design procedures for the unregulated resonant converter based DCX can be summarized as follow steps.

\section{Step 1: Transformer Turns Ratio}

Firstly, according to the system input voltage and output voltage, the transformer turns ratio can be selected.

\section{Step 2: Resonant Capacitor Voltage Stress}

Capacitor is one of the most critical components in power electronics systems. The voltage stress on the capacitor will affect the system reliability. Thus, the resonant capacitor voltage stress is considered first. The maximum voltage stress for the resonant capacitor can be expressed as

$$
V_{\text {cr, } \max }=k \times V_{\text {in, } \max } / 2+\frac{P_{\mathrm{o}, \max }}{4 n f_{\mathrm{r}} C_{\mathrm{r}} V_{\mathrm{o}}}
$$



Fig. 18. Equivalent circuit for LLC resonant converter during deadtime.

For half-bridge, stacked structure, and full-bridge with frequency doubler operation, the coefficient $k$ equals 1 , which means that there is a dc bias voltage of $V_{\text {in }} / 2$ for the resonant capacitor. While for the full-bridge structure, the coefficient $k$ equals 0 . From (8), the minimum resonant capacitance value can be calculated when the input voltage and output power reach their maximum values.

\section{Step 3: Resonant Tank RMS Current}

The resonant inductor RMS currents at resonant frequency operation can be expressed as

$$
i_{L \mathrm{r}, \mathrm{rms}}=\sqrt{\frac{\pi^{2} I_{\mathrm{o}}^{2}}{8 n^{2}}+\frac{n^{2} V_{\mathrm{o}}^{2}}{32 L_{\mathrm{m}}^{2} f_{\mathrm{r}}^{2}}}
$$

Clearly, at resonant frequency operation, a large magnetizing inductance value is preferred to reduce the circuit RMS current and conduction loss.

\section{Step 4: ZVS Operation Consideration}

The equivalent circuit during deadtime can be shown in Fig. 18. Due to the very short period of deadtime, the magnetizing inductor current can be regarded as a constant current source. To satisfy the ZVS operation for the primary switch, the magnetizing inductor current and deadtime should be large enough to discharge the energy stored in the parasitic capacitors as shown below

$$
I_{L \mathrm{M}} \times t_{\text {dead }} \geqslant\left(2 C_{\text {oss }}+C_{\text {stray }}+C_{\mathrm{T}}+C_{\mathrm{j} 1}\right) \cdot V_{\mathrm{i}}
$$

where $t_{\text {dead }}$ is the deadtime, $C_{\text {oss }}$ is the primary switch equivalent junction capacitance, $C_{\text {stray }}$ is the printed circuit board (PCB) stray capacitance, $C_{\mathrm{T}}$ is the transformer stray capacitance, $C_{\mathrm{j} 1}$ is the equivalent junction capacitance of the secondary rectifier. To ensure high accuracy, the primary switch and secondary rectifier junction capacitance cannot be considered constant since during the deadtime, the voltage across the primary switch and secondary rectifier is varying, so an equivalent junction capacitance should be used instead of a constant junction capacitance. The details regarding the analysis and calculation of equivalent 
junction capacitance for semiconductors can be found in [83].

The magnetizing inductor current during deadtime can be expressed as

$$
I_{L \mathrm{M}}=\frac{n V_{\mathrm{o}}}{2 f_{\mathrm{r}} L_{\mathrm{m}}}
$$

Combing (10) and (11), the maximum magnetizing inductance or the minimum deadtime can be calculated, which can be used to design the resonant converters based DCXs. A large inductor ratio value or magnetizing inductance value is beneficial to compensate the resonant components tolerances as we analyzed in Part $\mathrm{C}$ of Section III.

\section{System Stability Verification}

As we discussed in Section III, for the cascaded or twostage systems, the system instability issue may occur due to the impedance interactions of these two converters in each stage. Therefore, once the converter parameters have been finalized. The impedance information should be derived to evaluate the system stability and modifications on the design may require to satisfy the system stability requirement.

\section{CONClusion}

In this article, we have reviewed the resonant converters based DC transformers. The DCXs have the main advantages of: 1) unity gain operation; 2) high efficiency operation; 3) simple synchronous rectification driving strategy; 4) simple deadtime analysis and control strategy; 5) sable and reliable operation; 6) good EMI performance with fixed switching frequency operation. Nevertheless, to maximize and maintain the benefit of DCXs, the output voltage regulation and automatic resonant frequency tracking capabilities should be carefully considered when designing the system. By overviewing and summarizing the existing solutions for these two major issues, a comprehensive system level and converter level design guidelines are provided for engineers when designing a resonant converter based DCX. In addition, a clear understanding of the operations, characteristics, issues, and solutions can be obtained from this article.

\section{REFERENCES}

[1] F. Blaabjerg, R. Teodorescu, M. Liserre, and A. V. Timbus, "Overview of control and grid synchronization for distributed power generation systems," in IEEE Transactions on Industrial Electronics, vol. 53, no. 5, pp. 1398-1409, Oct. 2006.

[2] J. M. Carrasco, L. G. Franquelo, J. T. Bialasiewicz, E. Galvan, R. C. PortilloGuisado, M. A. M. Prats, J. I. Leon, and N. Moreno-Alfonso, "Power-electronic systems for the grid integration of renewable energy sources: A survey," in IEEE Transactions on Industrial Electronics, vol. 53, no. 4, pp. 1002-1016, Jun. 2006.

[3] F. Blaabjerg, Z. Chen, and S. B. Kjaer, "Power electronics as efficient interface in dispersed power generation systems," in IEEE Transactions on Power Electronics, vol. 19, no. 5, pp. 1184-1194, Sept. 2004.

[4] X. Liu, P. Wang, and P. C. Loh, "A hybrid AC/DC microgrid and its coordination control," in IEEE Transactions on Smart Grid, vol. 2, no. 2, pp. 278-286, Jun. 2011.

[5] N. Eghtedarpour and E. Farjah, "Power control and management in a hybrid AC/DC microgrid," in IEEE Transactions on Smart Grid, vol. 5, no. 3, pp. 1494-1505, May 2014.
[6] J. Huang, J. Xiao, C. Wen, P. Wang, and A. Zhang, "Implementation of bidirectional resonant DC transformer in hybrid AC/DC micro-grid," in IEEE Transactions on Smart Grid, vol. 10, no. 2, pp. 1532-1542, Mar. 2019.

[7] B. Yang, F. C. Lee, A. J. Zhang, and G. Huang, "LLC resonant converter for front end DC/DC conversion," in Proceedings of APEC. Seventeenth Annual IEEE Applied Power Electronics Conference and Exposition (Cat. No.02CH37335), Dallas, TX, USA, 2002, pp. 1108-1112.

[8] H. Wu, Y. Jia, F. Yang, L. Zhu, and Y. Xing, "Two-stage isolated bidirectional DC-AC converters with three-port converters and two DC buses," in IEEE Journal of Emerging and Selected Topics in Power Electronics, vol. 8, no. 4, pp. 4428-4439, Dec. 2020.

[9] X. Fang, H. Hu, Z. J. Shen, and I. Batarseh, "Operation mode analysis and peak gain approximation of the LLC resonant converter," in IEEE Transactions on Power Electronics, vol. 27, no. 4, pp. 1985-1995, Apr. 2012.

[10] Y. -C. Liu, C. Chen, K. -D. Chen, Y. -L. Syu, and N. A. Dung, "Highfrequency and high-efficiency isolated two-stage bidirectional DC-DC converter for residential energy storage systems," in IEEE Journal of Emerging and Selected Topics in Power Electronics, vol. 8, no. 3, pp. 1994-2006, Sept. 2020.

[11] H. -S. Kim, M. -H. Ryu, J. -W. Baek, and J. -H. Jung, "High-efficiency isolated bidirectional AC-DC converter for a DC distribution system," in IEEE Transactions on Power Electronics, vol. 28, no. 4, pp. 1642-1654, Apr. 2013.

[12] A. Sankar, A. Mallik, and A. Khaligh, "Extended harmonics based phase tracking for synchronous rectification in CLLC converters," in IEEE Transactions on Industrial Electronics, vol. 66, no. 8, pp. 6592-6603, Aug. 2019.

[13] M. -H. Ryu, H. -S. Kim, J. -W. Baek, H. -G. Kim, and J. -H. Jung, "Effective test bed of 380-V DC distribution system using isolated power converters," in IEEE Transactions on Industrial Electronics, vol. 62, no. 7, pp. 4525-4536, Jul. 2015.

[14] B. Li, M. Chen, X. Wang, N. Chen, X. Sun, and D. Zhang, "An optimized digital synchronous rectification scheme based on time-domain model of resonant CLLC circuit," in IEEE Transactions on Power Electronics, vol. 36, no. 9, pp. 10933-10948, Sept. 2021

[15] P. He and A. Khaligh, "Comprehensive analyses and comparison of 1 kW isolated DC-DC converters for bidirectional EV charging systems," in IEEE Transactions on Transportation Electrification, vol. 3, no. 1, pp. 147-156, Mar. 2017.

[16] Y. Wei, Q. Luo, and A. Mantooth, "Overview of modulation strategies for LLC resonant converter," in IEEE Transactions on Power Electronics, vol. 35, no. 10, pp. 10423-10443, Oct. 2020.

[17] P. Hu, R. Yin, Z. He, and C. Wang, "A modular multiple DC transformer based DC transmission system for PMSG based offshore wind farm integration," in IEEE Access, vol. 8, pp. 15736-15746, 2020.

[18] R. Li and F. Shi, "Control and optimization of residential photovoltaic power generation system with high efficiency isolated bidirectional DCDC converter," in IEEE Access, vol. 7, pp. 116107-116122, 2019.

[19] Y. Wei, Q. Luo, and H. A. Mantooth, "An LLC converter with multiple operation modes for wide voltage gain range application," in IEEE Transactions on Industrial Electronics, vol. 68, no. 11, pp. 11111-11124, Nov. 2021.

[20] Y. Wei, Q. Luo, and A. H. Mantooth, "Synchronous rectification for LLC resonant converter: An overview," in IEEE Transactions on Power Electronics, vol. 36, no. 6, pp. 7264-7280, Jun. 2021.

[21] H. Wang, S. Dusmez, and A. Khaligh, "Maximum efficiency point tracking technique for LLC-based PEV chargers through variable DC link control," in IEEE Transactions on Industrial Electronics, vol. 61, no. 11, pp. 6041-6049, Nov. 2014.

[22] Z. -J. Su and Y. -S. Lai, "On-line DC-link voltage control of LLC resonant converter for server power applications," in Proceedings of 2014 IEEE Energy Conversion Congress and Exposition (ECCE), Pittsburgh, PA, USA, 2014, pp. 5422-5428.

[23] J. Lai, W. Lai, S. Moon, L. Zhang and A. Maitra, "A 15-kV class intelligent universal transformer for utility applications," in Proceedings of 2016 IEEE Applied Power Electronics Conference and Exposition (APEC), Long Beach, CA, USA, 2016, pp. 1974-1981.

[24] H. Ma, J. -S. Lai, C. Zheng, and P. Sun, "A high-efficiency quasi-singlestage bridgeless electrolytic capacitor-free high-power AC-DC driver for supplying multiple LED strings in parallel," in IEEE Transactions on Power Electronics, vol. 31, no. 8, pp. 5825-5836, Aug. 2016.

[25] S. -Y. Chen, Z. R. Li, and C. -L. Chen, "Analysis and design of singlestage AC/DC LLC resonant converter," in IEEE Transactions on Industrial Electronics, vol. 59, no. 3, pp. 1538-1544, Mar. 2012. 
[26] Y. Wei, Q. Luo, J. M. Alonso, and A. Mantooth, "A magnetically controlled single-stage AC-DC converter," in IEEE Transactions on Power Electronics, vol. 35, no. 9, pp. 8872-8877, Sept. 2020.

[27] X. Sun, Y. Shen, Y. Zhu, and X. Guo, "Interleaved boost-integrated LLC resonant converter with fixed-frequency PWM control for renewable energy generation applications," in IEEE Transactions on Power Electronics, vol. 30, no. 8, pp. 4312-4326, Aug. 2015.

[28] Q. Liu, Q. Qian, B. Ren, S. Xu, W. Sun, and L. Yang, “A two-stage buckboost integrated LLC converter with extended ZVS range and reduced conduction loss for high-frequency and high-efficiency applications," in IEEE Journal of Emerging and Selected Topics in Power Electronics, vol. 9, no. 1, pp. 727-743, Feb. 2021.

[29] Z. Ye, P. K. Jain, and P. C. Sen, "Phasor-domain modeling of resonant inverters for high-frequency AC power distribution systems," in IEEE Transactions on Power Electronics, vol. 24, no. 4, pp. 911-923, Apr. 2009.

[30] A. Emadi, A. Khaligh, C. H. Rivetta, and G. A. Williamson, "Constant power loads and negative impedance instability in automotive systems: definition, modeling, stability, and control of power electronic converters and motor drives," in IEEE Transactions on Vehicular Technology, vol. 55, no. 4, pp. 1112-1125, Jul. 2006.

[31] R. D. Middlebrook and S. Cuk, "A general unified approach to modelling switching-converter power stages," in Proceedings of 1976 IEEE Power Electronics Specialists Conference, Cleveland, OH, USA, Jun. 1976, pp. $18-34$.

[32] Y. Wei, Q. Luo, S. Chen, J. Huang, and L. Zhou, "DC current bus distributed power system and its stability analysis," in IET Power Electronics, vol. 12, no. 3, pp. 458-464, Mar. 2019.

[33] S. Tian, F. C. Lee, and Q. Li, "Equivalent circuit modeling of LLC resonant converter," in IEEE Transactions on Power Electronics, vol. 35, no. 8, pp. 8833-8845, Aug. 2020.

[34] B. -C. Kim, K. -B. Park, C. -E. Kim, B. -H. Lee, and G. -W. Moon, "LLC resonant converter with adaptive link-voltage variation for a high-powerdensity adapter," in IEEE Transactions on Power Electronics, vol. 25, no. 9, pp. 2248-2252, Sept. 2010.

[35] C. Shi, H. Wang, S. Dusmez, and A. Khaligh, "A SiC-based highefficiency isolated onboard PEV charger with ultrawide DC-link voltage range," in IEEE Transactions on Industry Applications, vol. 53, no. 1, pp. 501-511, Jan.-Feb. 2017

[36] C. Shi, A. Khaligh, and H. Wang, "Interleaved SEPIC power factor preregulator using coupled inductors in discontinuous conduction mode with wide output voltage," in IEEE Transactions on Industry Applications, vol. 52, no. 4, pp. 3461-3471, Jul.-Aug. 2016.

[37] J. Lu, A. Mallik, S. Zou, and A. Khaligh, "Variable DC-link control loop design for an integrated two-stage AC/DC converter," in IEEE Transactions on Transportation Electrification, vol. 4, no. 1, pp. 99-107, Mar. 2018.

[38] B. Zhao, X. Zhang, and J. Huang, "AI algorithm-based two-stage optimal design methodology of high-efficiency CLLC resonant converters for the hybrid AC-DC microgrid applications," in IEEE Transactions on Industrial Electronics, vol. 66, no. 12, pp. 9756-9767, Dec. 2019.

[39] J. Huang, X. Zhang, Z. Shuai, X. Zhang, P. Wang, L. H. Koh, J. Xiao, and X. Tong, "Robust circuit parameters design for the CLLC-type DC transformer in the hybrid AC-DC microgrid," in IEEE Transactions on Industrial Electronics, vol. 66, no. 3, pp. 1906-1918, Mar. 2019.

[40] Y. Jia, H. Wu, Y. Zhang, Y. Liu, and Y. Xing, "Single-phase ACDC converter with dual-output rectifier, dual-input DC transformer, and voltage-split/sigma principle," in IEEE Transactions on Power Electronics, vol. 35, no. 1, pp. 158-168, Jan. 2020.

[41] W. Dai, J. Chen, X. Chen, T. Zhang, and C. Gong, "Two-stage aviation rectifier based on cascaded H-bridge," in Proceedings of 2018 IEEE 27th International Symposium on Industrial Electronics (ISIE), Cairns, QLD, Australia, 2018, pp. 451-455.

[42] T. Xia, P. Xu, H. Wu, W. Sun, and Y. Chen, "A semi-regulated dual-output llc resonant converter for two-stage multiple-output conversion with wide input voltage range," in Proceedings of 2015 IEEE 10th Conference on Industrial Electronics and Applications (ICIEA), Auckland, New Zealand, 2015, pp. 1170-1174.

[43] H. Wu, C. Wan, K. Sun, and Y. Xing, "A high step-down multiple output converter with wide input voltage range based on quasi two-stage architecture and dual-output LLC resonant converter," in IEEE Transactions on Power Electronics, vol. 30, no. 4, pp. 1793-1796, Apr. 2015.

[44] M. H. Ahmed, C. Fei, F. C. Lee, and Q. Li, "48-V voltage regulator module with PCB winding matrix transformer for future data centers," in IEEE Transactions on Industrial Electronics, vol. 64, no. 12, pp. 9302-
9310, Dec. 2017.

[45] M. Ahmed, C. Fei, F. C. Lee, and Q. Li, "High efficiency two-stage 48 V VRM with PCB winding matrix transformer," in Proceedings of 2016 IEEE Energy Conversion Congress and Exposition (ECCE), Milwaukee, WI, USA, 2016, pp. 1-8.

[46] C. Fei, M. H. Ahmed, F. C. Lee, and Q. Li, "Two-stage 48 V-12 V/6 $\mathrm{V}-1.8 \mathrm{~V}$ voltage regulator module with dynamic bus voltage control for light load efficiency improvement of two-stage voltage regulator," in IEEE Transactions on Power Electronics, vol. 32, no. 7, pp. 5628-5636, Jul. 2017.

[47] J. Y. Zhu and B. Lehman, "Control loop design for two-stage DC-DC converters with low voltage/high current output," in IEEE Transactions on Power Electronics, vol. 20, no. 1, pp. 44-55, Jan. 2005.

[48] Y. -C. Liu, C. Chen, K. -D. Chen, Y. -L. Syu, and N. A. Dung, "Highfrequency and high-efficiency isolated two-stage bidirectional DC-DC converter for residential energy storage systems," in IEEE Journal of Emerging and Selected Topics in Power Electronics, vol. 8, no. 3, pp. 1994-2006, Sept. 2020.

[49] C. Zhang, P. Li, Z. Kan, X. Chai, and X. Guo, "Integrated half-bridge CLLC bidirectional converter for energy storage systems," in IEEE Transactions on Industrial Electronics, vol. 65, no. 5, pp. 3879-3889, May 2018.

[50] F. Liu, X. Ruan, X. Huang, and Y. Qiu, "Second harmonic current reduction for two-stage inverter with DCX-LLC resonant converter in front-end DC-DC converter: Modeling and control," in IEEE Transactions on Power Electronics, vol. 36, no. 4, pp. 4597-4609, Apr. 2021.

[51] F. Liu, G. Zhou, X. Ruan, S. Ji, Q. Zhao, and X. Zhang, "An inputseries-output-parallel converter system exhibiting natural input-voltage sharing and output-current sharing," in IEEE Transactions on Industrial Electronics, vol. 68, no. 2, pp. 1166-1177, Feb. 2021.

[52] J. -Y. Lee, Y. -S. Jeong, and B. -M. Han, "An isolated DC/DC converter using high-frequency unregulated LLC resonant converter for fuel cell applications," in IEEE Transactions on Industrial Electronics, vol. 58, no. 7, pp. 2926-2934, Jul. 2011.

[53] X. Sun, J. Qiu, X. Li, B. Wang, L. Wang, and X. Li, "An improved wide input voltage buck-boost + LLC cascaded converter," in Proceedings of 2015 IEEE Energy Conversion Congress and Exposition (ECCE), Montreal, QC, Canada, 2015, pp. 1473-1478.

[54] M. Fu, C. Fei, Y. Yang, Q. Li, and F. C. Lee, "Optimal design of planar magnetic components for a two-stage GaN-based DC-DC converter," in IEEE Transactions on Power Electronics, vol. 34, no. 4, pp. 3329-3338, Apr. 2019.

[55] Y. Cai, M. H. Ahmed, Q. Li, and F. C. Lee, "Optimal design of megahertz LLC converter for 48-V bus converter application," in IEEE Journal of Emerging and Selected Topics in Power Electronics, vol. 8, no. 1, pp. 495-505, Mar. 2020.

[56] T. M. Tuan and W. Choi, "A novel two-stage power conversion method suitable for LDCs of the electric vehicles," in Proceedings of 2019 10th International Conference on Power Electronics and ECCE Asia (ICPE 2019 - ECCE Asia), Busan, Korea (South), 2019, pp. 1-7.

[57] P. Jia, Z. Huang, Y. Hao, Q. Chen, and S. Fan, "A two-stage isolated converter without intermediate capacitor for wide voltage range applications," in Proceedings of 2019 IEEE Energy Conversion Congress and Exposition (ECCE), Baltimore, MD, USA, 2019, pp. 1315-1320.

[58] M. H. Ahmed, C. Fei, F. C. Lee, and Q. Li, "Single-stage high-efficiency 48/1 V sigma converter with integrated magnetics," in IEEE Transactions on Industrial Electronics, vol. 67, no. 1, pp. 192-202, Jan. 2020.

[59] M. Xu, Y. Liu, J. Sun, and F. C. Lee, " $\Sigma /$ sigma DC/DC conversion for computing and telecom applications," in Proceedings of 2008 IEEE Power Electronics Specialists Conference, Rhodes, Greece, 2008, pp. 1190-1195.

[60] M. Li, Z. Ouyang, and M. A. E. Andersen, "A hybrid multitrack-sigma converter with integrated transformer for wide input voltage regulation," in Proceedings of 2020 IEEE Applied Power Electronics Conference and Exposition (APEC), New Orleans, LA, USA, 2020, pp. 1844-1850.

[61] Y. Li, X. Lyu, Z. Ni, J. Johnson, and D. Cao, “An isolated composite resonant multilevel converter with partial power voltage regulation for telecom application," in Proceedings of 2018 IEEE Energy Conversion Congress and Exposition (ECCE), Portland, OR, USA, 2018, pp. 3831-3837.

[62] Y. Wei, Q. Luo, X. Lv, P. Sun, and X. Du, "Analysis and design of function decoupling high voltage gain DC/DC converter", in Journal of Power Electronics, vol. 19, no. 2, pp. 380-393, Mar. 2019.

[63] Y. Wei, Q. Luo, and A. Mantooth, "A hybrid half-bridge LLC resonant converter and phase shifted full-bridge converter for high step-up 
application", in Proceedings of 2020 IEEE Workshop on Wide Bandgap Power Devices and Applications in Asia (WiPDA Asia), Suita, Japan, 2020.

[64] Y. Liao, T. Peng, M. Su, Y. Sun, W. Xiong, and G. Xu, "A bidirectional DAB-LLC DCX to achieve voltage regulation and wide ZVS range capability," in Proceedings of 2020 22nd European Conference on Power Electronics and Applications (EPE'20 ECCE Europe), Lyon, France, 2020, pp. 1-8.

[65] Y. Liao, G. Xu, Y. Sun, T. Peng, M. Su, B. Guo, and W. Xiong, "Singlestage DAB-LLC hybrid bidirectional converter with tight voltage regulation under DCX operation," in IEEE Transactions on Industrial Electronics, vol. 68, no. 1, pp. 293-303, Jan. 2021.

[66] Y. Wei, Q. Luo, X. Du, N. Altin, A. Nasiri, and J. M. Alonso, "A dual halfbridge LLC resonant converter with magnetic control for battery charger application," in IEEE Transactions on Power Electronics, vol. 35, no. 2, pp. 2196-2207, Feb. 2020.

[67] Y. Wei, N. Altin, Q. Luo, and A. Nasiri, "A high efficiency, decoupled on-board battery charger with magnetic control," in Proceedings of 2018 7th International Conference on Renewable Energy Research and Applications (ICRERA), Paris, France, 2018, pp. 920-925.

[68] H. -N. Vu and W. Choi, "A novel dual full-bridge LLC resonant converter for $\mathrm{CC}$ and $\mathrm{CV}$ charges of batteries for electric vehicles," in IEEE Transactions on Industrial Electronics, vol. 65, no. 3, pp. 2212-2225, Mar. 2018.

[69] H. J. Chiu, Y. K. Lo, P. J. Tseng, and Y. C. Liu, "High-efficiency battery charger with cascode output design," in IET Power Electronics, vol. 7, no. 7, pp. 1725-1735, Jul. 2014

[70] X. Wu, H. Chen, and Z. Qian, "1-MHz LLC resonant DC transformer (DCX) with regulating capability," in IEEE Transactions on Industrial Electronics, vol. 63, no. 5, pp. 2904-2912, May 2016.

[71] L. Zhang, X. Wu, and H. Chen, "1MHz LLC resonant DC-DC converter with PWM output regulation capability," in Proceedings of 2016 IEEE 8th International Power Electronics and Motion Control Conference (IPEMC-ECCE Asia), Hefei, China, 2016, pp. 445-450.

[72] $\mathrm{H}$. Li and $\mathrm{Z}$. Jiang, "On automatic resonant frequency tracking in LLC series resonant converter based on zero-current duration time of secondary diode," in IEEE Transactions on Power Electronics, vol. 31, no. 7, pp. 4956-4962, Jul. 2016

[73] W. Feng, P. Mattavelli, and F. C. Lee, "Pulsewidth locked loop (PWLL) for automatic resonant frequency tracking in LLC DC-DC transformer (LLC-DCX)," in IEEE Transactions on Power Electronics, vol. 28, no. 4 pp. 1862-1869, Apr. 2013.

[74] W. Feng, F. C. Lee, P. Mattavelli, and D. Huang, "A universal adaptive driving scheme for synchronous rectification in LLC resonant converters," in IEEE Transactions on Power Electronics, vol. 27, no. 8, pp. 3775-3781, Aug. 2012.

[75] S. Jiang, W. Zhang, B. Liu, and F. Wang, "Automatic resonant frequency tracking in unregulated LLC resonant converters based on total resonant current harmonic calculation," in Proceedings of 2013 IEEE Energy Conversion Congress and Exposition, Denver, CO, USA, 2013, pp. 4193-4198.

[76] Y. -S. Lai and M. -H. Yu, "Online autotuning technique of switching frequency for resonant converter considering resonant components tolerance and variation," in IEEE Journal of Emerging and Selected Topics in Power Electronics, vol. 6, no. 4, pp. 2315-2324, Dec. 2018.

[77] U. Kundu and P. Sensarma, "A unified approach for automatic resonant frequency tracking in LLC DC-DC converter" in IEEE Transactions on Industrial Electronics, vol. 64, no. 12, pp. 9311-9321, Dec. 2017.

[78] U. Kundu and P. Sensarma, "Gain-relationship-based automatic resonant frequency tracking in parallel LLC converter," in IEEE Transactions on Industrial Electronics, vol. 63, no. 2, pp. 874-883, Feb. 2016.

[79] U. Kundu and P. Sensarma, "A generalized low-cost solution for resonan frequency tracking in LLC converters," in Proceedings of 2018 IEEE International Conference on Power Electronics, Drives and Energy Systems (PEDES), Chennai, India, 2018, pp. 1-6.

[80] Y. Wei, Q. Luo, Z. Wang, and A. Mantooth, "Transformer secondary voltage based resonant frequency tracking for LLC converter," in IEEE Transactions on Circuits and Systems II: Express Briefs, vol. 68, no. 4, pp. 1243-1247, Apr. 2021.

[81] F. Lin, X. Zhang and X. Li, "Design methodology for symmetric CLLC resonant DC transformer considering voltage conversion ratio, system stability and efficiency," in IEEE Transactions on Power Electronics, vol. 36, no. 9, pp. 10157-10170, Sept. 2021.

[82] Y. Wei, Q. Luo, S. Chen, P. Sun, and N. Altin, "Comparison among different analysis methodologies for LLC resonant converter," in IET
Power Electronics, vol. 12, no. 9, pp. 2236-2244, Aug. 7, 2019

[83] M. Kasper, R. M. Burkart, G. Deboy, and J. W. Kolar, "ZVS of power MOSFETs revisited," in IEEE Transactions on Power Electronics, vol. 31, no. 12, pp. 8063-8067, Dec. 2016.

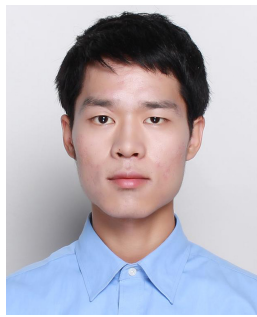

Yuqi Wei was born in Henan, China, in 1995. He received his B.S. degree in electrical engineering from Yanshan University, Hebei, China, in 2016, and his M.S. degree in electrical engineering from University of Wisconsin-Milwaukee (UWM), Wisconsin, U.S.A, in 2018. He received another M.S. degree in electrical engineering from Chongqing University, Chongqing, China, in 2019. He is currently working toward the Ph.D. degree at the University of Arkansas, Fayetteville, U.S.A.

His current research interests include topology, modelling and control of $\mathrm{DC} / \mathrm{DC}$ power converters and power factor correction $\mathrm{AC} / \mathrm{DC}$ converters, wide band gap devices, and active gate driving. Mr. Wei serves as Reviewer for IEEE Transactions on Industrial Electronics, IEEE Transactions on Power Electronics, IEEE Transactions on Industry Applications, Journal of Emerging and Selected Topics in Power Electronics, IEEE Access, and IET Power Electronics. He is also a recipient of the 2020 second place transaction paper award for IEEE Transaction on Power Electronics.



Quanming Luo was born in Chongqing, China, in 1976. He received his B.S., M.S., and Ph.D. degrees in electrical engineering from Chongqing University, in 1999, 2002, and 2008, respectively. He was with the Emerson Network Power Co. Ltd., Shenzhen, China, as a Research and Development Engineer from 2002 to 2005. Since 2005, he has been with the College of Electrical Engineering, Chongqing University, where he is currently a Professor. His current research interests include LED driving systems, communication power systems, power harmonic suppression, and power conversion systems in electrical vehicles.

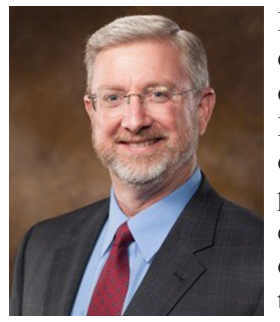

Homer Alan Mantooth received the B.S. and M.S degrees in electrical engineering from the University of Arkansas in 1985 and 1986, respectively, and the $\mathrm{Ph} . \mathrm{D}$. degree from the Georgia Institute of Technology in 1990. He then joined Analogy, a startup company in Oregon, where he focused on semiconductor device modeling and the research and development of modeling tools and techniques. In 1998, he joined the faculty of the Department of Electrical Engineering at the University of Arkansas, Fayetteville, where he currently holds the rank of Distinguished Professor. His research interests now include analog and mixed-signal IC design \& CAD, semiconductor device modeling, power electronics, and power electronic packaging. Dr. Mantooth helped establish the National Center for Reliable Electric Power Transmission (NCREPT) at the UA in 2005. Professor Mantooth serves as the Executive Director for NCREPT as well as two of its centers of excellence: the NSF Industry/University Cooperative Research Center on GRid-connected Advanced Power Electronic Systems (GRAPES) and the Cybersecurity Center on Secure, Evolvable Energy Delivery Systems (SEEDS) funded by the U.S. Department of Energy. In 2015, he also helped to establish the UA's first NSF Engineering Research Center entitled Power Optimization for Electro-Thermal Systems (POETS) that focuses on high power density systems for transportation applications. Dr. Mantooth holds the 21st Century Research Leadership Chair in Engineering. He serves as Immediate Past-President for the IEEE Power Electronics Society in 2019-20 and the Editor-in-Chief of IEEE Open Journal of Power Electronics. Dr. Mantooth is a Fellow of IEEE, a member of Tau Beta Pi and Eta Kappa Nu, and registered professional engineer in Arkansas. 